\title{
聚合物纳米药物用于治疗脑胶质瘤的最新 研究进展
}

\author{
孙雅静, 王一斌, 刘艳杰, 邹艳”, 郑蒙, 师冰洋* \\ 河南大学生命科学学院, 河南大学-麦考瑞生物医学联合创新中心, 开封 475004 \\ * 联系人, E-mail: bs@henu.edu.cn; yzou@henu.edu.cn \\ 收稿日期：2019-11-12; 接受日期：2019-12-06; 网络版发表日期：2020-05-12
}

\begin{abstract}
摘要脑胶质瘤是杪内最常见的原发性恶性肿瘤, 死亡率极高. 目前针对脑胶质瘤的治疗手段预后差, 难以实现 良好的治疗效果。基于高分子聚合物的纳米药物以其良好的生物相容性、便于设计合成、易于靶向修饰以及较 高的血脑屏障穿透效率等特性为脑胶质瘤的治疗开辟了新思路。基于高分子聚合物的纳米载体通过包载或键合 等方式与小分子抗癌药物、核酸(DNA, siRNA)、蛋白质等治疗类物质结合提高抗肿瘤效果. 本文综述了近年来 对脑胶质瘤采用的化学治疗、基因治疗、免疫治疗、协同治疗等多种治疗方式及刺激响应性聚合物纳米载体的 研究进展, 并对其未来发展进行了展望.
\end{abstract}

关键词聚合物, 纳米药物, 脑胶质瘤, 治疗方式

脑胶质瘤作为威胁人类健康的癌症之一，是中枢 神经系统最常见和最具有侵袭性的原发性恶性肿瘤, 并且其发病率呈逐年上升的趋势 ${ }^{[1]}$. 胶质瘤患者的中 位生存期一般小于一年，即使在最有利的条件下治疗， 患者的术后生存期仅为 2 年 ${ }^{[2,3]}$. 目前, 手术切除、放射 治疗和化学治疗是脑胶质瘤的主要治疗手段. 虽然手 术切除与放化疗在一定程度上改善了中位生存期，但 脑胶质瘤患者的预后仍然很差(中位生存期最高为 14

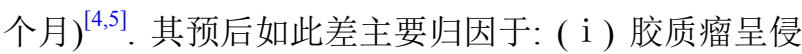
袭性生长, 通常正常组织与肿瘤组织没有明显的界限, 无法完全切除病灶组织; (ii) 放、化疗往往只能杀死 一定比例的肿瘤细胞，并且对正常组织带来严重的副 作用，造成患者免疫力下降 ${ }^{[6]}$; (iii) 血脑屏障(blood brain barrier, BBB)和血管脑肿瘤屏障(blood brain tumor barrier, BBTB)将绝大多数抗癌药物阻滞在外, 致 使肿瘤部位药物浓度过低以致无法杀死肿瘤细胞 ${ }^{[7,8]}$; (iv) 由于肿瘤干细胞和耐药性问题的存在, 胶质瘤极 其容易复发 ${ }^{[9]}$. 因此, 克服目前肿瘤治疗的局限性, 设 计和制备安全高效的治疗方式刻不容缓.

近年来，纳米药物的飞速发展为脑胶质瘤的治疗 带来了新的希望. 纳米药物以纳米尺寸的分子作为载 体，以包裹或键合等方式与抗癌药物结合. 与游离的 小分子抗肿瘤药物相比，纳米药物具有表面积大、药 代动力学稳定性增强及毒副作用显著降低等特点, 在 提高抗癌药物的生物利用率、穿透BBB、控制释放和 降低耐药性等许多方面均有不可替代的优越性，具有

引用格式: 孙雅静, 王一斌, 刘艳杰, 等. 聚合物纳米药物用于治疗脑胶质瘤的最新研究进展. 中国科学: 生命科学, 2021, 51: 819-835

Sun Y J, Wang Y B, Liu Y J, et al. Recent advances in polymeric nanomedicines for glioblastoma therapy (in Chinese). Sci Sin Vitae, 2021, 51: 819-835, doi: 10.1360/SSV-2019-0212 
十分广阔的研究和开发前景 ${ }^{[10 \sim 12]}$.

基于高分子聚合物的纳米载体具有极大的优势, 如便利的设计与合成、适当的粒径和粒形、良好的生 物相容性、较高的载药效率、可生物降解性等, 因此, 其引起了研究者们的广泛关注. 常见的聚合物纳米载 体根据结构的不同可分为胶束、囊泡、纳米凝胶等. 为了提高聚合物纳米药物的药物释放, 一系列基于 $\mathrm{pH}$ 敏感、还原敏感、酶敏感、光敏感、超声敏感等内在 或外界刺激响应的聚合物纳米载体被开发并用于治疗 包括胶质瘤在内的多种癌症, 从而有效实现抗癌药物 的控制释放 ${ }^{[13 \sim 15]}$. 相比于其他部位的肿瘤, 脑胶质瘤 的治疗由于 BBB和BBTB的存在更为棘手. BBB是一 道维持脑内环境稳定和阻挡有害物质入侵的天然屏 障, 由毛细血管内皮细胞通过紧密连接形成, 能够限制 $100 \%$ 的大分子药物和 $98 \%$ 的小分子药物进入脑 内 $^{[16 ~ 18]}$. 随着脑胶质瘤的发展, BBB的完整性受到一 定程度的破坏而形成BBTB. BBTB存在于脑胶质瘤细 胞和毛细血管之间, 阻碍了纳米载体进入肿瘤的有效 运输 ${ }^{[19]}$. 因此, 大多数用于治疗脑胶质瘤的药物都不 能穿透BBB与BBTB进入脑内, 从而难以治愈脑胶质 瘤患者. 目前, 研究者大多通过在纳米载体表面修饰 抗体、多肽、核酸适配体等分子以实现主动靶向并穿 透BBB和BBTB的目的, 从而达到更好的脑胶质瘤治 疗效果.

如图1所示, 本文从聚合物纳米载体的角度出发, 简要叙述了目前对脑胶质瘤采用的化学治疗、基因治
疗、免疫治疗和协同治疗等多种治疗方式的研究进 展, 并对目前广泛采用的化学治疗进行了较为详细的 评述.

\section{1 化学治疗}

近年来, 化学治疗显著提高了脑胶质瘤患者的生 存率, 在脑胶质瘤的综合治疗中占有极其重要的地 位. 化学治疗始于 20 世纪 40 年代末 50 年代初, 随着 新型抗癌药物的出现而不断进步. 化学治疗一般用于 手术切除后或与放疗同时进行. 长期以来, 由于化学 药物体内易代谢、难以穿透BBB与BBTB、严重的毒 副作用以及耐药机制等问题的存在, 该治疗方式对脑 胶质瘤的治疗效果不尽人意. 近些年, 纳米技术的出 现及不断发展为化学治疗提供了新的机遇. 基于高分 子纳米药物的化学治疗出现最早, 并且仍然是当前研 究最热的治疗方式之一. 将治疗脑胶质瘤的化学药物 以包裹或键合等方式与聚合物纳米载体结合, 形成的 纳米药物通过血液循环到达胶质瘤部位, 有效穿透 BBB和BBTB并进行响应释放, 从而杀死肿瘤细胞来 抑制胶质瘤生长并最终延长患者的生存周期. 现阶 段, 不计其数的化疗药物用于与纳米技术联合治疗脑 胶质瘤, 例如, 目前纳米载体包裹的常见化疗药物包 括替莫唑胺、阿霉素、顺铂等. 研究表明, 与自由药 物相比, 包裹后的纳米药物在体内外均有明显提升的 治疗效果(表1).
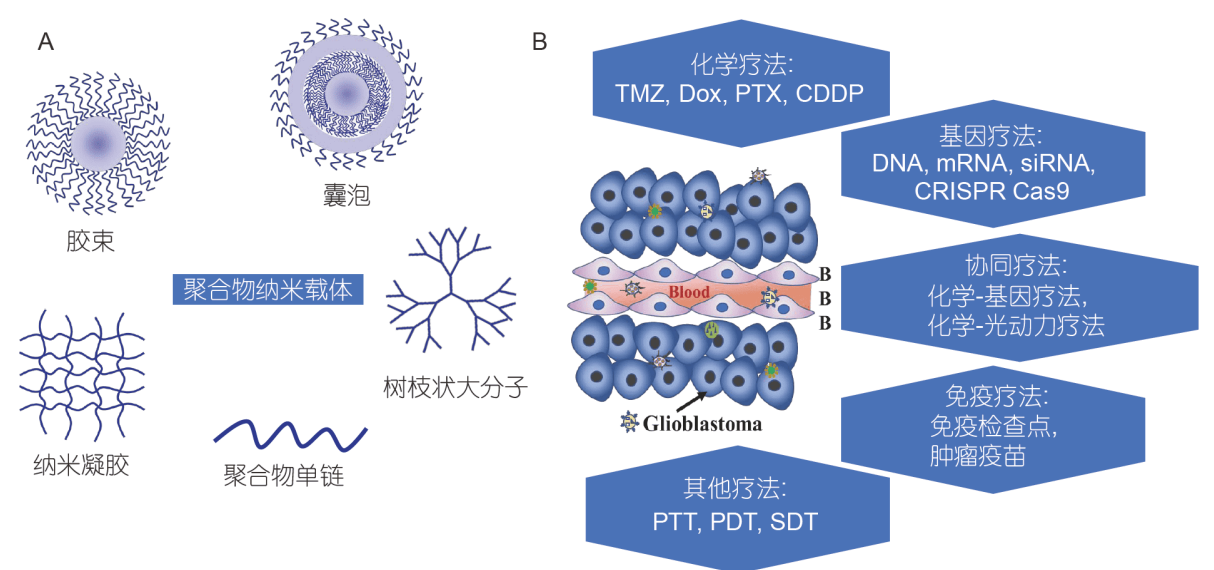

图 1 聚合物纳米药物用于脑胶质瘤的治疗. A: 聚合物纳米载体的分类; B: 聚合物纳米药物通过不同的疗法, 如化学治疗、 基因治疗、免疫治疗用于脑胶质瘤治疗的示意图(网络版彩图)

Figure 1 Polymeric nanomedicines for the treatment of glioblastoma (GBM). A: Classification of polymeric nanocarriers; B: schematic illustration of polymeric nanomedicines treating glioblastoma via various therapy methods such as chemotherapy, gene therapy, and immunotherapy (Color online) 
表 1 聚合物纳米载体用于人脑胶质瘤的化学治疗

Table 1 Summary of polymeric nanoparticles applied for glioblastoma chemotherapy

\begin{tabular}{|c|c|c|c|c|c|c|}
\hline 药物 & 聚合物载体 & 靶向配体 & 粒径(nm) & 细胞/动物模型 & 抗肿瘤效果 & 参考文献 \\
\hline \multirow{2}{*}{$\begin{array}{c}\text { 替莫唑胺 } \\
\text { temozolomide } \\
\text { (TMZ, 疏水) }\end{array}$} & $\begin{array}{c}\text { 甲基丙烯酸酯聚合物 } \\
\text { polyMPC }\end{array}$ & - & $\begin{array}{c}7 \\
24 \sim 38\end{array}$ & $\begin{array}{c}\text { U87MG } \\
\text { T98G(体外) }\end{array}$ & $\begin{array}{l}\text { 半衰期约为游离TMZ的 } \\
\text { 2 19倍, 提高抗肿瘤效率 }\end{array}$ & {$[20]$} \\
\hline & $\begin{array}{c}\text { 聚乳酸-羟基乙酸 } \\
\text { PLGA }\end{array}$ & $\begin{array}{l}\text { OX26型转铁蛋白 } \\
\text { 受体单克隆抗体 }\end{array}$ & $194 \pm 1$ & $\begin{array}{c}\mathrm{U} 251 \\
\mathrm{U} 87 \mathrm{MG} \text { (体外) }\end{array}$ & $\begin{array}{c}\mathrm{IC}_{50} \text { 减小至游离 } \mathrm{TMZ} \text { 的 } 1 / \\
4((15 \pm 2) \mu \mathrm{mol} / \mathrm{L}), \text { 有效抑 } \\
\text { 制肿瘤细胞生长 }\end{array}$ & {$[21]$} \\
\hline $\begin{array}{c}\mathrm{TMZ} \\
\text { 6-芐基鸟嘌呤 } \\
\mathrm{O}^{6} \text {-benzylguanine(亲水) }\end{array}$ & PLGA & - & $<200$ & - & $\begin{array}{l}\text { TMZ包封率提高(56.7\%) } \\
\text { 并降低其耐药性 }\end{array}$ & {$[22]$} \\
\hline \multirow[t]{2}{*}{$\begin{array}{c}\text { 阿需素 } \\
\text { doxorubicin } \\
\text { (Dox, 疏水) }\end{array}$} & PLGA & 白蛋白 & $135 \pm 11$ & U87MG(体外) & $\begin{array}{c}\text { 细胞内吞比游离Dox提 } \\
\text { 高4.9倍, 调亡基因的表 } \\
\text { 达量增高至原来的 }(5.4 \\
\pm 0.8) \text { 倍, 有效杀死肿瘤 } \\
\text { 细胞 }\end{array}$ & {$[23]$} \\
\hline & PLGA & 聚羟亚烃 188 & $120 \pm 1$ & U87MG(体外) & $\begin{array}{c}\text { 受体介导高效穿透BBB, } \\
\text { 抑制肿瘤细胞的增殖 }\end{array}$ & {$[24]$} \\
\hline $\begin{array}{c}\text { Dox } \\
\text { lexiscan } \\
\text { (Lex, 疏水) }\end{array}$ & $\begin{array}{c}\text { 缩醛葡聚糖 } \\
\text { Ac-DEX }\end{array}$ & angiopep-2 & 约 200 & $\begin{array}{l}\text { U87MG原位荷瘤 } \\
\text { 裸鼠(体内外) }\end{array}$ & $\begin{array}{c}\text { 延长血液循环时间, 提高 } \\
\mathrm{BBB} \text { 穿透性, 显著延长中 } \\
\text { 位生存期(38天) }\end{array}$ & {$[25]$} \\
\hline \multirow{3}{*}{$\begin{array}{c}\text { 甲氨蝶呤 } \\
\text { methotrexate } \\
\text { (MTX, 疏水) }\end{array}$} & PLGA & - & $150 \sim 200$ & U87MG(体外) & $\begin{array}{c}\text { 细胞毒性增强 }(35.2 \%) \text {, } \\
\text { 显著降低对 } \mathrm{MTX} \text { 的 } \mathrm{IC}_{50} \\
\text { 值 }(0.7 \mu \mathrm{g} / \mathrm{mL})\end{array}$ & {$[26]$} \\
\hline & PLGA & $\begin{array}{l}\text { 聚羟亚烃 } 188 \\
\text { 聚乙烯醇 }\end{array}$ & $170 \sim 330$ & - & $\begin{array}{l}\text { 尺寸和理化性质更合适, } \\
\text { 进一步提高抗肿瘤活性 }\end{array}$ & {$[27]$} \\
\hline & PLGA & $\begin{array}{l}\text { 转铁蛋白 } \\
\text { 叶酸 }\end{array}$ & $109 \pm 2$ & $\begin{array}{c}\text { C6原位荷瘤大鼠 } \\
\text { (体内外) }\end{array}$ & $\begin{array}{c}\text { 高效穿透BBB, 肿瘤体积 } \\
\text { 为非靶向修饰组的 } 1 / 3\end{array}$ & {$[28]$} \\
\hline \multirow{2}{*}{$\begin{array}{c}\text { 紫杉醇 } \\
\text { paclitaxel } \\
\text { (PTX, 疏水) }\end{array}$} & $\begin{array}{c}\text { 甲氧基聚乙二醇-聚己 } \\
\text { 内醌-己内酰胺 } \\
\text { MPEG }\end{array}$ & - & $73 \pm 2$ & $\begin{array}{c}\text { C6原位荷瘤裸鼠 } \\
\text { (体内外) }\end{array}$ & $\begin{array}{l}\text { 改善PTX水溶性差的问 } \\
\text { 题, 延长生存中值(26天) }\end{array}$ & [29] \\
\hline & $\begin{array}{c}\text { 聚乙二醇化聚(L- } \gamma \text {-谷 } \\
\text { 氨酰谷氨酰胺) } \\
\text { PEG-PGG }\end{array}$ & $\begin{array}{l}\text { 肿瘤穿透肽 } \\
\text { RGERPPR }\end{array}$ & 90 & $\begin{array}{l}\text { U87MG原位荷瘤 } \\
\text { 裸鼠(体内外) }\end{array}$ & $\begin{array}{c}\text { 肿瘤部位大量积累, 较强 } \\
\text { 的细胞杀伤作用, 显著延 } \\
\text { 长中位生存期(47天) }\end{array}$ & {$[30]$} \\
\hline $\begin{array}{l}\text { PTX } \\
\text { TMZ }\end{array}$ & $\begin{array}{c}\text { 纳米水凝胶 } \\
\text { (基于聚乙二醇) }\end{array}$ & - & $190 \pm 4$ & $\begin{array}{l}\text { U87MG肿瘤切除 } \\
\text { 裸鼠(体内外) }\end{array}$ & $\begin{array}{c}\text { 耐受良好, 有效抑制肿瘤 } \\
\text { 复发, 实现长期存活 }\end{array}$ & {$[31]$} \\
\hline \multirow{2}{*}{$\begin{array}{c}\text { 顺铂 } \\
\text { cisplatin } \\
\text { (CDDP, 疏水) }\end{array}$} & $\begin{array}{c}\text { 聚氧基丙烯酸丁酯 } \\
\text { PBCA }\end{array}$ & - & $451 \pm 11$ & $\begin{array}{l}\text { A172 } \\
\text { (体外) }\end{array}$ & $\begin{array}{l}\text { 显著减小对 } \mathrm{CDDP} \text { 的 } \mathrm{IC}_{50} \\
\text { 值( }(25.4 \pm 3.1) \mu \mathrm{mol} / \mathrm{L}) \text {, 有 } \\
\text { 效诱导肿瘤细胞的凋亡 }\end{array}$ & {$[32]$} \\
\hline & $\begin{array}{c}\text { 聚乳酸- } b \text {-聚乙二醇 } \\
\text { PLGA-P-PEG }\end{array}$ & 终端三苯基膦 & 未提及 & $\begin{array}{l}\text { J2TBG和SDT3G胶 } \\
\text { 质瘤荷瘤小猎犬 }\end{array}$ & $\begin{array}{l}\text { 肿瘤铂积累量较高, 有效 } \\
\text { 降低线粒体活性, 且对正 } \\
\text { 常组织无毒副作用 }\end{array}$ & {$[33]$} \\
\hline
\end{tabular}

\section{1 抗肿瘤烷化剂一一替莫唑胺}

替莫唑胺(temozolomide, TMZ)是治疗脑胶质瘤的 一线化疗药物. TMZ作为一种DNA烷基化剂, 可使 DNA的鸟嘌呤和腺嘌呤碱基甲基化，导致DNA双链断 裂, 细胞周期阻滞, 最终诱导细胞凋亡.

Emrick课题组 ${ }^{[20]}$ 采用可逆加成-断裂链转移聚合 (reversible addition-fragmentation chain-transfer, RAFT)
的方式将含有 TMZ的甲基丙烯酸酯单体合成一系列 分子量不同的聚合物-药物偶联物. 结果表明，该偶联 纳米药物具有良好的纳米结构(粒径7 $\mathrm{nm}$ 或 $24 \sim 38 \mathrm{~nm}$ ) 和较高的TMZ载药量, 并且稳定性强, 在水溶液中的 半衰期是游离TMZ的2 19倍. 随后分别在TMZ敏感 $\mathrm{U} 87 \mathrm{MG}$ 与 TMZ耐药T98G两种胶质瘤细胞中, 证明了 该纳米药物与自由 TMZ相比, 具有更好的内吞效果及 
更高的抗肿瘤效率.

Pereira课题组 ${ }^{[21]}$ 报道了受体介导的包载TMZ的聚 乳酸-乙醇酸纳米粒子用于多形性脑胶质瘤的治疗. OX26型转铁蛋白受体单克隆抗体修饰的纳米载体, 可 以主动靶向胶质瘤细胞, 使 TMZ在肿瘤部位积累足够 的量. 他们利用U251和U87MG两种脑胶质瘤细胞系 对药物的体外BBB穿透和细胞毒性进行了评估, 结果 表明, 与自由 TMZ相比, 该纳米药物能够较好地穿透 $\mathrm{BBB}$, 并且在 $\mathrm{U} 251$ 细胞系中, $\mathrm{IC}_{50}$ (半抑制浓度, 本文是 指凋亡细胞与全部细胞数比值为 $50 \%$ 时所对应的药物 浓度)值显著减小 $((15 \pm 2) \mu \mathrm{mol} / \mathrm{L})$, 细胞毒性更强, 有效 抑制了肿瘤细胞的生长.

然而, TMZ在脑胶质瘤的治疗中效果并不理想, 这归因于高水平表达 $\mathrm{O}^{6}$-甲基鸟嘌呤-DNA 甲基化转移 酶 $\left(\mathrm{O}^{6}\right.$-methylguanine-DNA methyltransferase, MGMT) 的存在, MGMT可以修复TMZ甲基化的DNA, 使脑胶 质瘤细胞对TMZ产生耐药性 ${ }^{[34,35]}$. Pereira课题组 ${ }^{[22]}$ 采 用优化聚乳酸-羟基乙酸(poly(D,L-lactic-co-glycolic), $\mathrm{PLGA})$ 纳米载体共递送 $\mathrm{TMZ}$ 和 $\mathrm{O}^{6}$-茮基鸟嘌呤 $\left(\mathrm{O}^{6}\right.$-benzylguanine)用于脑胶质瘤的治疗. 通过分数因子设计 得到最优化的PLGA纳米制剂, 该载体可以同时递送 $\mathrm{TMZ}$ 和 $\mathrm{O}^{6}$-苄基鸟嘌呤至脑胶质瘤部位. 细胞实验结 果表明, $\mathrm{O}^{6}$-苄基鸟嘌呤为强效的MGMT抑制剂, 能够 降低MGMT的稳定性及对DNA的亲和力, 增加其对蛋 白酶的敏感性, 有效改善脑胶质瘤细胞对TMZ的敏感 性. 该多功能纳米系统能有效缓解MGMT高表达引发 的TMZ耐药性难题, 为脑胶质瘤的治疗带来了曙光.

\section{2 抗肿瘤抗生素——阿霉素}

阿霉素(doxorubicin, Dox或adriamycin, ADR), 蒽 环类抗肿瘤抗生素, 是一种广谱类抗癌药物. Dox具有 极强的细胞毒性, 主要通过其结构中的葱醌嵌入DNA 分子中, 引起DNA裂解, 从而抑制核糖核酸的合成, 达 到杀死肿瘤细胞的目的 ${ }^{[36,37]}$. 研究结果表明, Dox被包 裹进入纳米载体后, 能有效改变其体内药代动力学, 延 长循环时间, 增加血药浓度, 减小肿瘤细胞的耐药性, 从而提高抗肿瘤效果.

Tekade课题组 ${ }^{[23]}$ 报道了采用树枝状阳离子聚合物 与白蛋白杂合得到的纳米粒子, 其能有效提高BBB的 穿透性和Dox的抗肿瘤活性. 细胞实验结果证明, 经该 纳米药物处理后的细胞毒性(66\%)明显高于自由Dox,
且 $\mathrm{BBB}$ 穿透能力高约十倍. 在 $360 \mathrm{~min}$ 内细胞摄取率为 $73.6 \%$, 相比非改性纳米粒子提高了 1.6 倍, 比游离Dox 提高了 4.9 倍. 细胞调亡基因的表达量增高至原来的 $(5.4 \pm 0.8)$ 倍, 能有效杀死肿瘤细胞.

Gelperina课题组 ${ }^{[24]}$ 通过聚羟亚烃 188 包裹负载 Dox的PLGA纳米粒子, 以增强其BBB穿透性. 大量研 究表明, 聚羟亚烃 188 涂层能够针定血液载脂蛋白 (ApoE, ApoA-I等), 这些载脂蛋白随后与脑毛细血管 内皮细胞表面的相关受体相互作用, 从而引发纳米颗 粒的BBB高效转运. 研究结果表明, 负载Dox的PLGA 纳米药物通过网格蛋白介导的内吞作用, 有效被人脑 胶质瘤 $\mathrm{U} 87 \mathrm{MG}$ 细胞摄取, 在溶酶体内微酸环境下降解 并释放Dox, 最终有效降低肿瘤细胞的存活率.

为了进一步解决BBB穿透的难题, 本课题组 ${ }^{[25]}$ 近 期构建了一种同时包载Dox和lexiscan(Lex)的仿生靶 向纳米药物(Ang-RBCm@NM-(Dox/Lex)). 红细胞膜 包裹可改善纳米药物的生物相容性, 其表面修饰的Angiopep-2通过与BBB内皮细胞和脑胶质瘤细胞表面过 表达的低密度脂蛋白受体(low density lipoprotein receptor-1, LPR-1)特异识别而有效穿透BBB和靶向肿瘤 部位. 同时, Lex能短暂打开BBB, 进一步提高AngRBCm@NM-(Dox/Lex)的BBB穿透能力. 该仿生纳米 药物内核由缩醛键接枝的葡聚糖组成, 能在内涵体的 酸性环境下水解, 快速释放负载的Lex和Dox. Lex短暂 地打开BBB, 进一步促进该纳米颗粒的脑穿透, 从而形 成一个递增循环, 更好地穿透BBB并在肿瘤部位积聚, 最终有效杀死肿瘤细胞. 体内实验结果表明, 该纳米药 物具有明显延长血液循环时间、提高BBB穿透性、改 善肿瘤积累和滞留能力等优点. 更重要的是, AngRBCm@NM-(Dox/Lex)能有效抑制U87MG原位荷瘤 裸鼠肿瘤增长, 存活时间显著延长(中位生存期为 38 天)且无毒副作用(图2).

\section{3 抗肿瘤抗代谢药物一甲氨蝶呤}

甲氨蝶呤 (methotrexate, MTX)为抗叶酸类抗肿瘤 药物, 主要通过抑制二氢叶酸还原酶的活性而阻碍 DNA的合成, 进而影响代谢过程, 抑制肿瘤细胞的生 长和增殖.

Khosravani课题组 ${ }^{[26]}$ 制备了负载MTX的PLGA纳 米系统, 粒径为150 200 nm, 可以实现MTX的缓慢持 续释放. 体外实验结果表明, 与自由MTX相比, 该纳米 

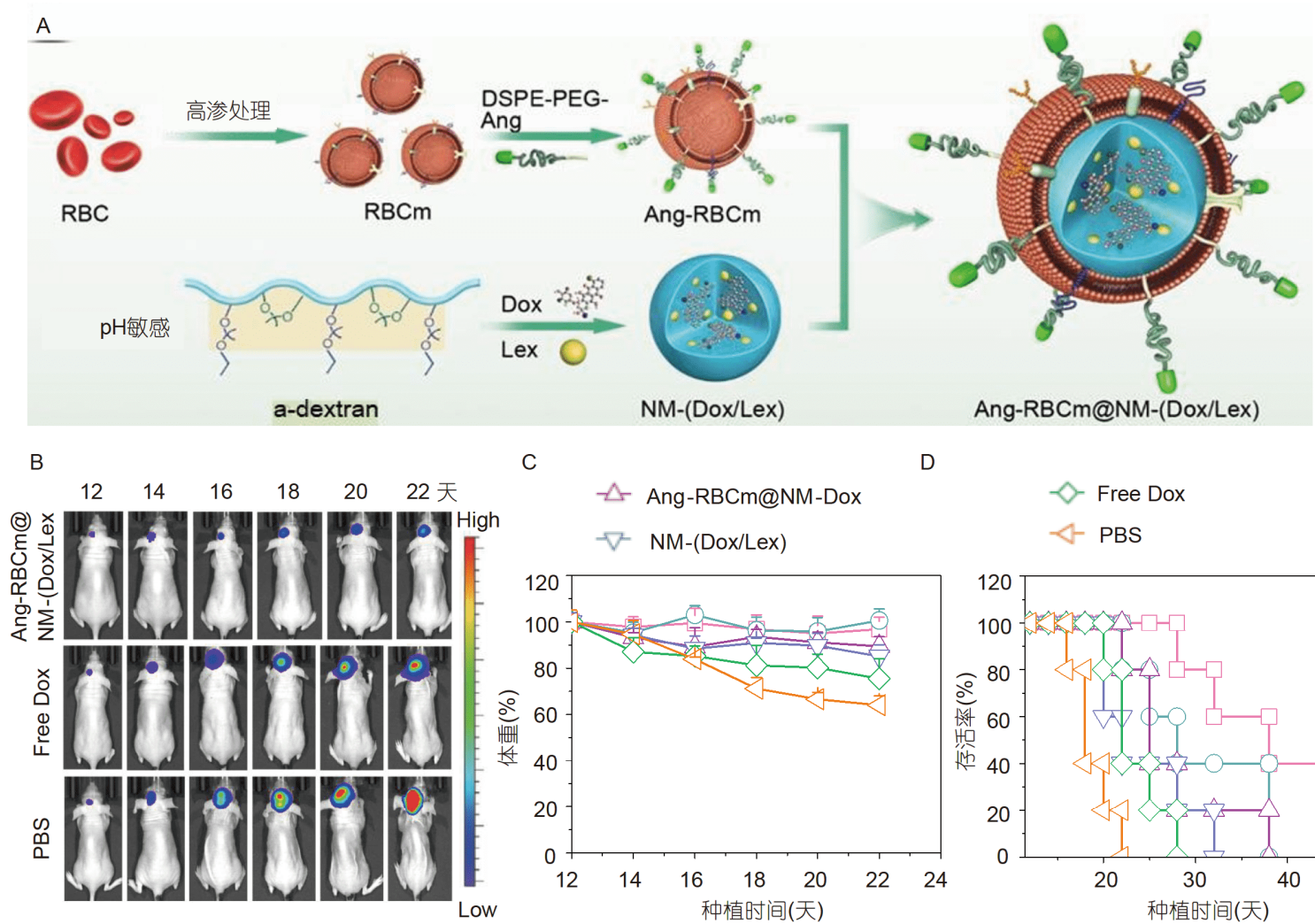

C
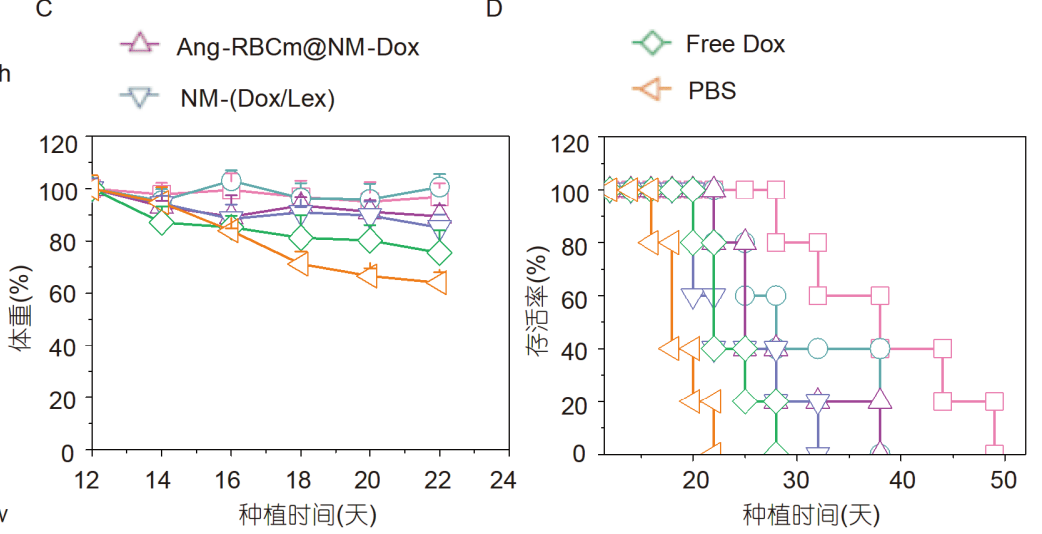

图 2 通过一种多功能仿生纳米药物有效和有针对性地治疗人原位脑胶质瘤. A: Ang-RBCm@NM-(Dox/Lex)的合成过程示 意图; B: Ang-RBCm@NM-(Dox/Lex)治疗U87MG原位荷脑胶质瘤裸鼠肿瘤的生物荧光示意图; 治疗期间裸鼠的(C)体重变化 及(D)生存时间 ${ }^{[25]}$ (网络版彩图)

Figure 2 Effective and targeted human orthotopic GBM xenograft therapy via a multifunctional biomimetic nanomedicine. A: Schematic illustration of formation of Ang-RBCm@NM-(Dox/Lex); B: the biofluorescence changes of U87MG orthotopic human glioblastoma tumor bearing nude mice following treatment with Ang-RBCm@NM-(Dox/Lex); (C) body weight change and, (D) survival rate during treatment ${ }^{[25]}$ (Color online)

药物不仅对U87MG 具有更高的细胞毒性, 且还能降低 $\mathrm{U} 87 \mathrm{MG}$ 细胞的 $\mathrm{IC}_{50}$ 值 $(0.7 \mu \mathrm{g} / \mathrm{mL})$. 随后, 该课题组分别 用聚羟亚烃188与聚乙烯醇(poly vinyl alcohol, PVA)两 种表面活性剂 ${ }^{[27]}$, 修饰该纳米粒子，使其具有更合适 的尺寸和理化性质，从而进一步提高其抗肿瘤活性. 由于MTX的BBB穿透能力较差，限制了它在脑胶质瘤 的治疗中的应用. Sharma课题组 ${ }^{[28]}$ 报道了转铁蛋白和 叶酸共同修饰负载MTX的聚合物纳米载体, 以克服难 以跨越BBB这一难题. 修饰后的纳米粒子通过受体介 导的内吞作用能有效靶向并胞吞进入脑肿瘤细胞, 转 铁蛋白分子作为一个归巢信号, 使得MTX在靶区域分 布并积累足够的剂量. 同时还采用吐温 80 表面活性剂 修饰该纳米粒子，增强其稳定性. 在C6原位脑胶质瘤 大鼠模型中, 该纳米药物能够高效穿透 $\mathrm{BBB}($ 约 $87 \%)$, 对C6胶质瘤细胞具有较强的抑制和调亡作用. 经尾静
脉注射该功能化纳米药物后，肿瘤体积显著减小 $73.6 \%$, 最终非靶向组肿瘤体积约是靶向组的 3.5 倍. 此 外, 吐温 80 的包裹使该纳米药物在体内的循环时间显 著延长, 是一种有效的胶质瘤预后治疗方式.

\section{4 植物类抗肿瘤药物——紫杉醇}

紫杉醇(paclitaxel，PTX)是双萜类化合物，通过稳 定微管蛋白抑制微管的分解, 使细胞分裂阻断在 $\mathrm{G} 2$ 期 和 $\mathrm{M}$ 期, 导致肿瘤细胞无法分裂而调亡. 然而, PTX的 极疏水、难以通过BBB等特性，在一定程度上限制了 其在脑胶质瘤临床化疗中的应用 ${ }^{[38]}$. 因此，改善PTX 的溶解性并使其靶向作用对其用于脑胶质瘤的化疗研 究意义重大.

Fang课题组 ${ }^{[29]}$ 构建了聚乙二醇化聚己内酯(polyethyleneglycol-polycaprolactone, PEG-PCL)负载PTX的 
纳米药物, 并探索了其抗脑胶质瘤效果. 制备得到的纳 米粒子结构稳定, 在 $4^{\circ} \mathrm{C}$ 条件下存放 21 天粒径无明显变 化. 该纳米药物不仅有效改善了PTX的溶解性, 而且具 有更强的细胞毒性, $\mathrm{IC}_{50}$ 值显著减小 $((1.4 \pm 0.2) \mu \mathrm{g} / \mathrm{mL})$. 相应地, 相比于注射自由PTX的脑胶质瘤荷瘤小鼠, 使 用该纳米颗粒治疗的小鼠存活时间延长了9天. 该纳米 药物成功地解决了PTX水溶性差的问题, 从而提高了 其肿瘤治疗效果.

近年来, 大量研究表明, 靶向配体修饰的纳米粒子 能够显著提高纳米药物的肿瘤靶向能力. Yu课题组 ${ }^{[30]}$ 提出利用肿瘤穿透肽共轭修饰包载PTX的聚合物纳米 颗粒, 使其具有主动靶向肿瘤部位的能力. 体外与体内 实验结果证明，修饰后的纳米粒子被内皮细胞以及 $\mathrm{U} 87 \mathrm{MG}$ 细胞的摄取明显增加. 与之相对应地, PTX在 肿瘤部位的积累量显著增加, 产生更强的细胞杀伤力, 显著延长了荷瘤小鼠的中位生存期(47天).

脑胶质瘤具有高度浸润性，术后极易复发，这也 成为治疗脑胶质瘤的重大难题. Préat课题组 ${ }^{[31]}$ 通过 可光解的纳米水凝胶 (PEG-DMA/PLGA) 同时负载 PTX和TMZ用于预防手术切除后脑胶质瘤的复发. PEG-DMA/PLGA可以在光照条件下水解, 释放出 PTX和TMZ, 实现肿瘤部位药物快速释放. 高剂量的 TMZ对正常骨髓有一定抑制作用，而PTX与 TMZ具 有不同的作用机制, 不重叠的毒性以及不同的耐药机 制. 众所周知, 不同作用机制的化疗药物联合使用有 助于提高抗肿瘤效果，达到协同治疗的目的. 体外实 验结果证明, PTX与 TMZ具有增效/协同作用。在 U87MG脑胶质瘤切除小鼠模型中，该纳米系统对小 鼠脑部耐受良好, 能有效抑制肿瘤复发, 并实现小鼠 长期存活.

\section{5 其他类药物}

除上述的几种常见抗癌化学药物外, 用于脑胶质 瘤的化疗药物还包括生物反应调节剂、细胞分化诱导 剂、顺铂类配合物以及近几年兴起的新型靶向抗肿瘤 药物等, 其中顺铂类配合物是目前应用最为广泛的抗 肿瘤药物. 以顺铂(cisplatin, CDDP)为例, CDDP是首 个具有抗肿瘤作用的重金属络合物，为有效的化疗药 物之一. 其作用机制主要是: 解离后形成的CDDP水合 阳离子，与DNA共价结合形成加合物，从而阻止DNA 的复制和RNA及蛋白质的合成(高浓度) ${ }^{[39]}$. 在治疗脑
胶质瘤的应用中, CDDP受到严重的全身毒性和BBB 穿透效率低下等限制 ${ }^{[40,41]}$. 研究者们采取了多种策略 解决上述难题, 目前最有效和最有前景的策略是通过 纳米系统定向递送CDDP至脑胶质瘤部位.

Khiyavi课题组 ${ }^{[32]}$ 报道了负载CDDP的聚氰基丙烯 酸丁酯纳米药物(PBCA-CDDP)用于治疗脑胶质瘤. 有 证据表明, $\mathrm{PBCA}$ 是首个用于将药物输送到中枢神经 系统的聚合物纳米载体, 相比于其他聚合物纳米载体, PBCA具有体积小、体外稳定性好、穿透BBB能力强 等优点. 该纳米颗粒进入A172胶质瘤细胞后, 能够快 速释放CDDP, 进而引发肿瘤细胞调亡. 细胞实验结果 表明, 该纳米药物显著减小脑胶质瘤细胞对 CDDP的 $\mathrm{IC}_{50}$ 值 $((25.4 \pm 3.1) \mu \mathrm{mol} / \mathrm{L})$, 相对于游离 CDDP, 该纳米 体系能有效诱导肿瘤细胞的凋亡, 产生较好的胶质瘤 治疗效果.

Dhar课题组 ${ }^{[33]}$ 采用末端三苯基膦(triphenylphosphine, TPP)功能化高分子亲脂性聚乳酸- $b$ - 聚乙二醇 (PLGA- $b-\mathrm{PEG)}$ 纳米载体负载经修饰的CDDP前药形成 线粒体靶向纳米粒, 并证明该纳米颗粒能够穿透 $\mathrm{BBB}$ 到达线粒体部位，随后 $\mathrm{CDDP}$ 前药被还原为 CDDP, 与 线粒体DNA交联, 阻断线粒体DNA核苷酸切除修复系 统, 从而迫使过活跃的肿瘤细胞调亡. 静脉注射该纳米 药物至健康成年小猎犬模型, 14 天的器官分布分析表 明, 纳米药物组在大脑中具有更高水平的铂积累, 而 在其他正常器官中几乎没有. 并且根据定期神经学检 查和脑脊液分析, 均未观察到神经毒性.

\section{2 基因治疗}

基因治疗是目前最具有前瞻性的治疗手段之一, 通过纳米载体将治疗核酸(DNA, message RNA (mRNA), small interfering RNA(siRNA), microRNA 等)导入目标组织或细胞的染色体中, 调控或替代异常 基因, 弥补肿瘤细胞的缺陷, 最终达到杀死肿瘤细胞的 目的 ${ }^{[2,43]}$. 在过去的几十年里, 超过 2000 个利用基因治 疗的临床实验通过调节癌变基因的表达或纠正突变基 因获得批准, 证明了基因治疗的特异性和高效性 ${ }^{[43]}$. 基因治疗主要包括三种方式: 基因的直接表达(DNA 或mRNA)、利用RNA干扰技术进行基因敲除( siRNA 或microRNA)以及CRISPR/Cas9(clustered regularly interspaced short palindromic repeats (CRISPR)/associated 
protein 9)基因编辑技术.

基因的直接表达是指将肿瘤细胞内突变或缺失 基因的DNA或mRNA转入，直接表达合成相应的蛋 白质, 抑制肿瘤的生长. Han课题组 ${ }^{[44]}$ 报道了组氨酸 和精氨酸功能化的聚氨基胺树突状大分子递送调亡 素DNA分子, 在体外诱导GBL-14和U373-MG原发性 脑胶质瘤细胞调亡. 聚氨基胺树突状大分子是一种结 构灵活的合成阳离子聚合物, 其基因表达量高、免疫 原性低，被广泛用作非病毒基因和药物载体. 组氨酸 和精氨酸的修饰使得该聚合物载体具有更强的缓冲 能力, 进而克服溶酶体难逃离的问题, 增强细胞内释 放，提高转染调亡素DNA活性，充分发挥细胞毒性. 聚氨基胺树突状大分子中的一级和三级内胺基被质 子化，并通过静电相互作用与带负电荷的调亡素 DNA形成纳米复合物. 当其进入细胞后, 肽键被水解 断裂, 释放负载的DNA. 实验结果证明, 功能化的纳 米复合物在人类原发性胶质瘤细胞GBL-14调亡期的 积聚量远高于非功能化组. 调亡素能够有效诱导胶质 瘤细胞调亡(36.2\%), 且对正常成纤维细胞没有毒副 作用.

Hanes 课题组 ${ }^{[45]}$ 采用聚 ( $\beta$-氨基酯) 与 $P E G$ 包覆 DNA形成纳米复合物, 并用于F98和9L GS两种原位脑 肿瘤的治疗. 高度聚乙二醇化的聚合物可以产生紧密 的和胶体稳态的DNA纳米颗粒，有效避免其黏附并滞 留于内皮细胞上, 从而在肿瘤组织快速渗透, 这对给药 后在体内实现原位脑肿瘤中转基因表达至关重要。实 验结果证明，在两种侵袭性原位脑胶质瘤模型中，与 未包覆纳米粒子中装载相同量DNA相比，该纳米药物 能显著延长大鼠的中位生存期(39天).

mRNA是一种天然的生物分子, 介导从DNA编码 的基因到位于细胞各处的蛋白质的翻译. 与DNA不同, mRNA只需要到达细胞质即可诱导蛋白表达，而且不 存在插入突变的明显风险 ${ }^{[46]}$. 有关mRNA的研究已有 半个多世纪的历史，但由于其可感知的不稳定性、易 降解性、翻译性不足以及免疫刺激作用，导致mRNA 在肿瘤治疗中的应用受到了限制。近年来，随着对 mRNA的结构与其稳定性的关系有了更深的理解，以 及各种化学修饰方法的发展, 人们对mRNA的癌症治 疗潜力越来越感兴趣 ${ }^{[47]}$. 有报道称，由阳离子聚合物 制备的纳米粒子可有效传递核酸 ${ }^{[48]}$. 然而，相对于已 开发的DNA递送技术，mRNA递送策略仍然需要更多
的改进和测试.

RNA干扰(RNA interference, RNAi) 是通过小干扰 RNA(siRNA) 实现目标mRNA特异性表达沉默的现 象 ${ }^{[49]}$. Zhou课题组 ${ }^{[50]}$ 报道了采用磁体和转铁蛋白共同 修饰的主动靶向性聚乙二醇-聚(L-赖氨酸)(polyethylene glycol-poly(L-lysine), PEG-PLL)纳米载体负载抗 Polo样蛋白激酶(polo-like kinase 1, PLK1)siRNA, 利用 RNAi技术治疗U87MG原发性脑胶质瘤. 磁体的修饰 能够使该纳米颗粒富集到脑胶质瘤部位，转铁蛋白通 过与脑毛细血管内皮细胞表面高表达的转铁蛋白受体 结合实现高效穿透BBB. PLK1，高表达于包括脑胶质 瘤细胞在内的多种肿瘤细胞，与脑胶质瘤预后差、易 复发密切相关. 该纳米粒子的粒径约为 $60 \mathrm{~nm}$, 能够将 siPLK1高效递送至脑胶质瘤细胞. 该纳米药物能有效 穿透BBB并诱导基因沉默，进而杀死肿瘤细胞. 在 U87MG原位脑胶质瘤小鼠模型中, 经该纳米载体递送 siPLK1治疗的小鼠肿瘤体积显著变小, 且具有最长的 生存时间( $>90$ 天).

迄今为止, 在脑胶质瘤的基因治疗策略中, 研究最 多的siRNA递送系统包括阳离子聚合物、阳离子脂质 体、阳离子无机纳米颗粒. 这些阳离子材料能够通过 电荷相互作用与带负电荷的siRNA结合成纳米颗粒, 并保护siRNA在体内不被RNA核糖核酸酶降解. 然而, 由于这些阳离子载体表面带有较高的正电荷, 通常会 破坏细胞膜的稳定性, 并对正常组织产生严重的细胞 毒性. 为了解决这一难题, 本课题组 ${ }^{[51]}$ 通过还原敏感 的二硫键将 $\mathrm{Zn}(\mathrm{II})$-二吡啶胺偶联到透明质酸聚合物上 形成配位聚合物, 从而开发了一种安全的siRNA递送 系统, $\mathrm{Zn}(\mathrm{II})$-二吡啶胺选择性地与 siRNA离子磷酸根 的配位络合, 形成稳定的siRNA纳米药物. 该功能化纳 米载体与传统的阳离子载体相比, 具有较低的正电荷, 对正常细胞/组织的毒性较弱. 该纳米药物被U87MG 脑胶质瘤细胞摄取后，在细胞内过量表达的谷胱甘肽 (glutathione, GSH)下触发释放siRNA，从而产生RNA 干扰效应。实验结果表明，该聚合物纳米载体具有较 好的生物相容性, 适用于siRNA的递送. 目标纳米粒子 的内化能力最高, 约是游离 siRNA内吞能力的 40 倍. 在 U87MG-luc脑胶质瘤异位小鼠模型中，该纳米药物基 因沉默效果最好，血液循环时间最长(消除半衰期 $34.7 \mathrm{~min}$ )，脑部积累量比自由荧光染料高5倍. 此外, 该纳米药物有效抑制了肿瘤体积的增长，抗肿瘤效果 
良好.

除此之外，血液中大量带电荷生物大分子的存在, 会干扰阳离子聚合物与siRNA之间的结合，使仅依赖 于静电相互作用维持稳定的siRNA纳米药物在体内处 于濒临分解的状态，从而缩短血液循环时间，阻碍 RNA干扰治疗效果. 鉴于此, 本课题组 ${ }^{[52]}$ 近期构建了 一种由静电、氢键和疏水作用三重相互作用稳定的聚 合 siRNA纳米药物(3I-NM@siRNA). 与仅依赖静电相 互作用的siRNA纳米制剂相比，加入额外的氢键和疏 水相互作用显著提高了生理稳定性(图3). 同时，3INM@siRNA显示出由肿瘤活性氧引发其序列不稳定, 导致负载siRNA的快速释放. 此外, 经angiopep-2修饰 获得主动靶向性的Ang-3I-NM@siRNA, 表现出较高的 BBB穿透效率和肿瘤聚集与积累. 该脑靶向纳米载体
共载siPLK1和抗血管内皮生长因子受体-2 siRNA，可 以同时下调靶基因的表达，有效地延缓胶质瘤的生长. Ang-3I-NM@siRNA的BBB穿透与肿瘤积聚分别为非 靶向组和游离siRNA的2.3和6倍. Ang-3I-NM@siRNA 联合靶向RNA干扰，能够有效抑制肿瘤生长，显著延 长了U87MG原位脑胶质瘤荷瘤裸鼠的生存时间(中位 生存期为 36 天).

CRISPR/Cas9技术是近些年发展起来的最有前途 的基因组编辑技术之一. 该技术使用一种经过特定设 计的单链向导RNA(single-guide RNA, sgRNA)将Cas9 核酸酶导向至其互补区域, Cas9在该区域裂解靶DNA 并发生双链断裂，导致特定目的基因组位点的插入或 缺失. 与RNAi技术不同，该技术诱导的基因组敲除是 永久地消除靶基因的DNA水平. 近年来，灵活高效的

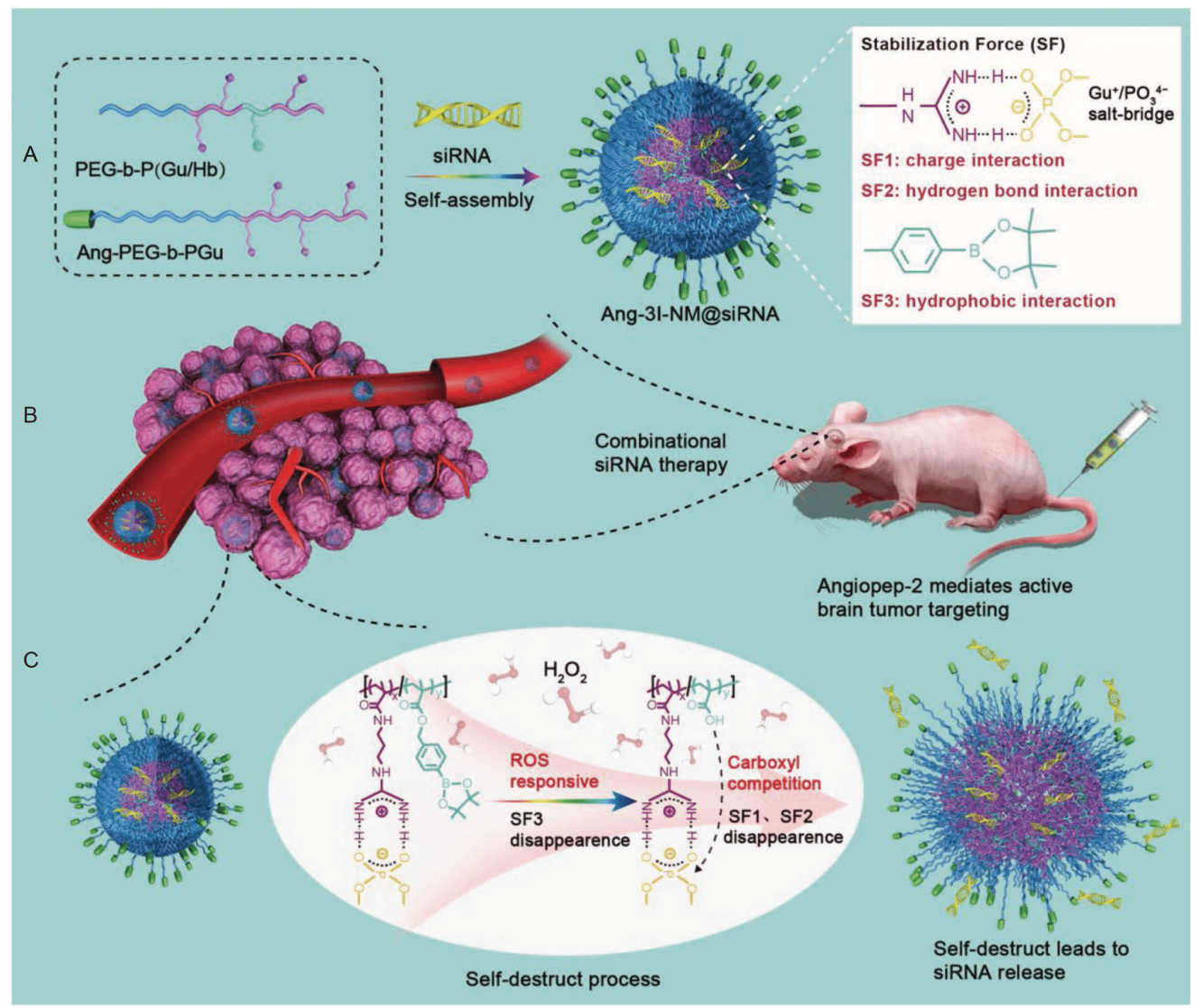

图 3 三重作用力稳定的ROS响应性聚合siRNA纳米药物用于恶性胶质母细胞瘤的联合RNAi治疗. A: Ang-3I-NM@siRNA的 形成示意图，由静电、氢键和疏水相互作用三种“三相互作用”力稳定；B：肿瘤的主动摄取和联合RNAi治疗；C：ROS触发 siRNA释放的机制 ${ }^{[52]}$ (网络版彩图)

Figure 3 ROS-responsive polymeric siRNA nanomedicine stabilized by triple interactions for the robust GBM combinational RNAi therapy. A: Schematic illustration of formation of Ang-3I-NM@siRNA stabilized by the three "triple-interaction" forces, namely, electrostatic, hydrogen bond, and hydrophobic interactions; B: active tumor uptake and combinational RNAi therapy; C: mechanisms of ROS triggered siRNA release ${ }^{[52]}$ (Color online) 
CRISPR/Cas9基因编辑技术已被探索用于转录调控和 基因组编辑等生物调节过程, 具有巨大的脑胶质瘤基 因治疗潜力. Zhou课题组 ${ }^{[53]}$ 报道了通过水凝胶纳米颗 粒靶向递送微环DNA、Cas9蛋白和sgRNA, 利用 CRISPR/Cas9基因编辑技术治疗脑胶质瘤. 该纳米药 物粒径为 $95 \mathrm{~nm}$, 细胞穿透肽iRGD的修饰使其具有更 高的细胞摄取率及较高的基因转染效率. 体外实验结 果表明, iRGD修饰的纳米颗粒可以被U87MG细胞和 GS5 脑肿瘤干细胞高效率内吞, 效率高达 $100 \%$. 以 PLK1 为基因模型, 与该纳米粒子共孵育的肿瘤细胞, PLK1的表达量显著下调，有效抑制了U87MG细胞和 脑肿瘤干细胞的增殖. 经尾静脉注射进入脑胶质瘤荷 瘤小鼠体内, 该纳米药物治疗组小鼠肿瘤体积为PBS 组的 $23.5 \%$, PKL1表达量仅为对照组的 $36.3 \%$, 并且核 质比明显下降.

\section{3 免疫治疗}

随着免疫学的快速发展, 免疫治疗为脑胶质瘤的 治疗带来了新的希望. 免疫治疗主要是通过增强免疫 系统的功能, 进而杀死肿瘤细胞, 达到治疗脑胶质瘤 的目的. 免疫治疗策略包括免疫检查点、功能化 $\mathrm{T}$ 细 胞、癌症疫苗、自然杀伤细胞以及单克隆抗体或重组 蛋白等. 免疫治疗能够引起持久的临床反应, 弥补中枢 神经系统的免疫豁免性 ${ }^{[54,55]}$. 免疫治疗提供了一种不 同于化学治疗和基因治疗的方法, 为脑胶质瘤的治疗 带来了新的希望.

免疫逃逸机制的存在阻止了足够的特异性细胞毒 性 $\mathrm{T}$ 细胞在脑胶质瘤细胞周围聚集, 造成该部位抗肿 瘤活性较低或几乎没有. 因此, 招募足够的脑胶质瘤 特异性的细胞毒性 $\mathrm{T}$ 细胞至病灶部位, 增强脑胶质瘤 细胞的免疫反应具有极其重要的意义. Jiang课题组 ${ }^{[56]}$ 报道了Angiopep-2和IP10-EGFRvIIIscFv 融合蛋白修饰 的PLGA纳米颗粒穿透BBB并在脑组织中积累, 与细 胞毒性 $\mathrm{T}$ 细胞相联合, 增强机体免疫反应和抗肿瘤活 性. Angiopep-2通过与内皮细胞和脑胶质瘤细胞表面 高表达的LPR-1结合, 介导纳米颗粒穿透BBB到达肿 瘤部位. IP10-EGFRvIIIscFv融合蛋白具有特异性结合 脑胶质瘤细胞表面EGFRvIII抗原的潜力, 进而招募活 化的 $\mathrm{CD} 8^{+} \mathrm{T}$ 淋巴细胞定位于脑胶质瘤细胞. 实验结果 表明, 该纳米粒子能够被较好地内吞, 并在脑胶质瘤部
位积累. 经该纳米药物治疗的脑胶质瘤荷瘤小鼠表现 出较强的抗肿瘤活性, 肿瘤体积显著减小, 生存时间 明显延长( $>100$ 天).

大量研究表明, 导致免疫治疗效果不佳的主要原 因是严重的免疫抑制微环境, 这是脑胶质瘤的一个显 著特征，与其预后差密切相关. 为了实现抗脑胶质瘤 免疫治疗的预期, 破坏免疫抑制微环境变得十分必要. Chen课题组 ${ }^{[57]}$ 开发了一种聚甘油功能化的纳米复合 物包载Dox, 用于脑胶质瘤的治疗. 有报道称, 聚甘油 具有良好的生物相容性、亲水性和较长的等离子半衰 期, 可以有效延长纳米复合物的体内循环时间. 该纳米 药物通过激活脑胶质瘤细胞的免疫原性, 有效调节脑 胶质瘤的免疫抑制微环境. 更重要的是, 该纳米药物 增强了树突状细胞的活化, 激活了脑胶质瘤细胞自噬, 进而激活树突状细胞及其抗原的表达, 增强抗脑胶质 瘤免疫反应. 该研究为通过纳米技术调节脑胶质瘤的 免疫微环境提供了新的视角.

抗原递呈细胞中抗原积累量低是阻碍脑胶质瘤有 效免疫治疗的障碍之一. 为了解决这一问题, Zhang课 题组 ${ }^{[58]}$ 以双重诱导响应的三嵌段共聚物聚羧酸甜莱 碱-聚(N-(2-(2-吡啶二硫代)甲基丙烯酰胺乙酯(PCB-SS-PDM-PDA)纳米颗粒为基础, 研制了一种具有高抗 原载量的混合“团弹”纳米疫苗. 三嵌段共聚物主链和 侧链的双重还原维持了该纳米粒子在生理环境中的稳 定性. 在脑胶质瘤细胞内外GSH浓度显著不同的情况 下，二硫键断裂释放负载的人工抗原与佐剂. 实验结 果证明, 该纳米疫苗明显提高了抗原递呈细胞的抗原 积累量, 有效促进了抗原递呈细胞即树突状细胞的成 熟, 进而激活抗原特异性 $\mathrm{CD} 8^{+}$和 $\mathrm{CD} 4^{+} \mathrm{T}$ 细胞反应, 增 强胶质瘤细胞免疫和体液免疫, 从而间接提高脑胶质 瘤治疗的疗效.

细胞毒性 $\mathrm{T}$ 淋巴细胞相关抗原-4(cytotoxic T lymphocyte antigen 4, CTLA-4)和程序性死亡分子-1(programmed death 1, PD-1)均为临床常用的免疫检查点, 表达于 $\mathrm{T}$ 细胞表面. 通常情况下, 抑制 $\mathrm{T}$ 细胞的激活或 成熟会造成肿瘤细胞的免疫逃逸. 阻断特定免疫检查 点, 可以有效增强抗肿瘤免疫反应. Ljubimova课题 组 ${ }^{[59]}$ 基于聚 $(\beta-\mathrm{L}$-苹果酸)天然生物聚合物支架开发了 纳米免疫偶联物, 用于共价结合CTLA-4和PD-1抑制剂 穿透BBB，激活脑胶质瘤荷瘤小鼠脑局部抗肿瘤免疫 反应(图4). 实验结果表明, 经该纳米颗粒治疗的原位 

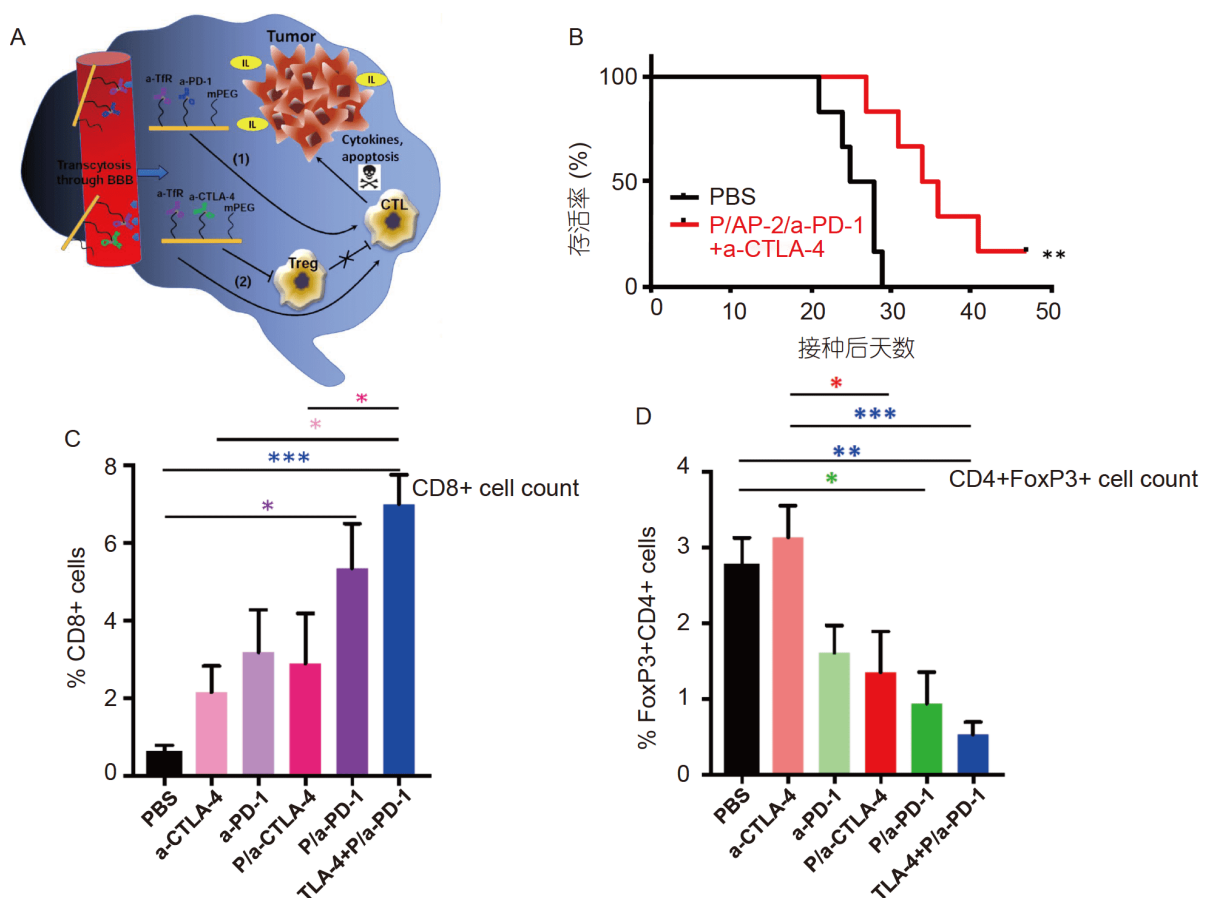

图 4 纳米免疫偶联物穿透血脑屏障激活局部脑肿瘤免疫系统治疗脑胶质瘤. A: 纳米药物穿透血脑屏障及a-CTLA-4和a-PD1抗体协同治疗脑胶质瘤的机制; B: 采用PBS, P/a-CTLA-4+P/a-PD-1治疗组的生存时间; P/a-PD-1和P/a-CTLA-4+P/a-PD-1治疗 导致肿瘤部位 $\mathrm{CD}^{+}$淋巴细胞显著增多 $(\mathrm{C}), \mathrm{CD}^{+} \mathrm{FoxP}^{+}$淋巴细胞显著减少 $(\mathrm{D})^{[59]}$. *: $P>0.05 ; * *: P>0.01 ; * * *: P>0.001$ (单因素 方差分析+图基事后检验)(网络版彩图)

Figure 4 Nano immunoconjugates crossing BBB activate local brain tumor immune system for GBM treatment. A: The proposed mechanism of synergistic treatment with a-CTLA-4 and a-PD-1 mAbs when they cross BBB as part of a nano-immunodrug; B: survival time after treatment with P/aCTLA-4+P/a-PD-1; treatments with P/a-PD-1 and P/a-CTLA-4+P/a-PD-1 result in a statistically significant increase of CD8 ${ }^{+}$lymphocytes $(C)$, and decrease of the number of $\mathrm{CD}^{+}{ }^{+}$FoxP $3^{+}$lymphocytes in the tumor $(\mathrm{D})^{[59]}{ }^{*}: P>0.05 ; * *: P>0.01 ; * * *: P>0.001$ (oneway ANOVA+Tukey's post-hoc test) (Color online)

GL261脑胶质瘤荷瘤小鼠, 脑肿瘤区CD8 ${ }^{+} \mathrm{T}$ 细胞增多, 调节 $\mathrm{T}$ 细胞减少, 并触发多种细胞因子的释放, 从而对 脑胶质瘤细胞产生免疫应答. 与游离CTLA-4和PD-1抑 制剂以及单载纳米药物治疗的小鼠相比，该纳米药物 较好的治疗效果主要表现在免疫应答强度和中位生存 期(46天)上.

\section{4 其他治疗}

光热疗法(photothermal therapy, PTT)是指利用光 诱导产生高热量杀死肿瘤细胞的治疗方式. 近年来, PTT因其对肿瘤的治疗效果好、对正常组织的损伤小 而备受关注. Liu课题组 ${ }^{[60]}$ 开发了一种双靶向配体修饰 的有机聚合物纳米颗粒来识别脑胶质瘤边缘，并实现 高效的光热治疗，抑制胶质瘤的生长. 该纳米颗粒具 有较好的光学性能, 较强的肿瘤边缘及内部靶向能力. 光热疗法对 $\mathrm{U} 87 \mathrm{MG}$ 细胞体外杀伤效果良好, 体内能够
有效抑制肿瘤的生长，且对神经元细胞的不良影响可 忽略不计. Cai课题组 ${ }^{[61]}$ 报道了采用氨基化巨噬细胞 膜包裹聚合物纳米载体，包载近红外荧光染料IR-792 形成可用于脑胶质瘤诊断与治疗的纳米药物(图5). 巨 噬细胞膜包裹使该纳米颗粒具有较好的生物相容性和 较强的BBB穿透能力. 近红外成像可以成功诊断原位 脑胶质瘤. 此外, 该纳米药物加激光治疗能有效诱导 $\mathrm{U} 87 \mathrm{MG}$ 细胞死亡，抑制原位脑胶质瘤生长，延长荷瘤 小鼠生存时间, 起到较好的抗肿瘤作用.

光动力疗法(photodynamic therapy, PDT)是一种基 于光敏剂、光和分子氧三个关键成分的微创局部治疗 方式. 通过适当的波长诱导光激发光敏剂与周围的氧 (或其他)分子发生光动力学反应，从而产生活性氧 ${ }^{[62]}$. 光敏剂本身具有较低的全身毒性，只有在光照下才具 有药理活性. 因此, PDT具有对正常组织损伤小、不 良反应少等优势. 与放化疗不同的是，PDT也可以在 同一部位重复进行, 终生不受剂量限制. Molinari课题 

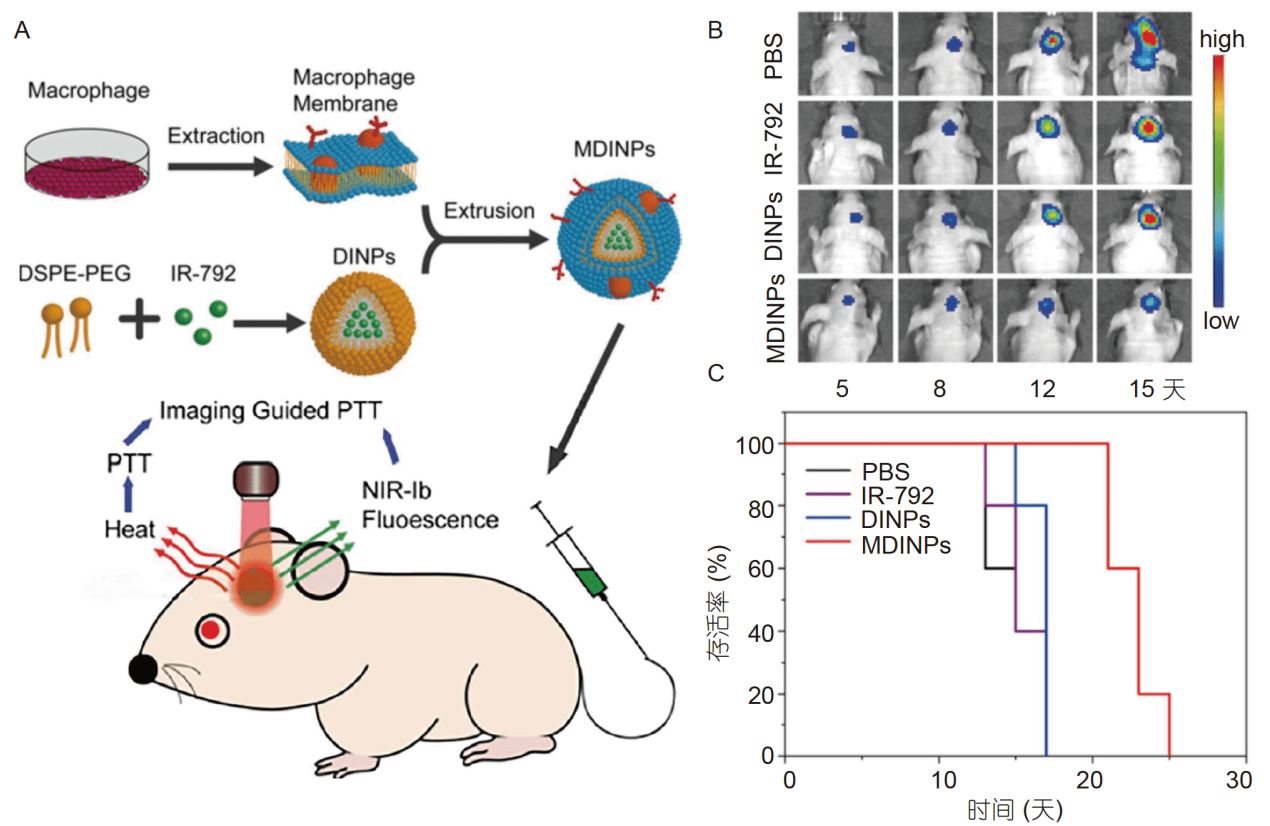

图 5 巨噬细胞仿生支架穿透血脑屏障对脑胶质瘤NIR-Ib成像诱导光热治疗. A: 纳米药物MDINPs制备示意图及通过近红外 光光热治疗脑胶质瘤; 荷瘤小鼠的肿瘤生物荧光成像(B)和生存周期 $(\mathrm{C})^{[61]}$ (网络版彩图)

Figure 5 Scaffolds biomimicking macrophages for a GBM NIR-Ib imaging guided photothermal therapeutic strategy by crossing BBB. A: Schematic illustration of the preparation of nanomedicines MDINPs and PTT anti-glioblastoma effect; tumor bioluminescence (B) and survival time (C) of tumor-bearing mice ${ }^{[61]}$ (Color online)

组 ${ }^{[63]}$ 报道了采用PLGA纳米载体包载疏水性光敏剂, 用于脑胶质瘤的光动力治疗. 该纳米颗粒粒径约为 $120 \mathrm{~nm}$, 并且在 5 天内结构稳定. 该纳米药物在非光照 条件下对C6脑胶质瘤细胞不具有毒性. 而在激光照射 后, 产生较强的细胞毒性, 细胞死亡率高达 $90 \%$.

声动力治疗 (sonodynamic therapy, SDT) 是指使用 集中超声波, 加热局部组织, 产生辐射力, 使肿瘤患者 立刻缓解并尽可能地避免损伤的治疗方式. 与PDT类 似，SDT也是通过超声激发产生活性氧来杀伤肿瘤细 胞. 此外, SDT具有光动力治疗所不具备的力学效应, 可以克服光激发治疗的深度限制，在临床应用上优于 $\mathrm{PDT}^{[64]}$. Wei课题组 ${ }^{[65]}$ 于 2010 年首次报道了超声可以 有效增强BBB的穿透, 有助于化疗药物更好地治疗脑 胶质瘤. 此外, 可通过激活一些超声敏化剂, 如卟啉、

5-氨基乙酰丙酸等产生活性氧促使胶质瘤细胞调亡, 这使得SDT为脑胶质瘤的治疗提供了新策略 ${ }^{[6]}$.

\section{5 协同治疗}

化学治疗、基因治疗和免疫治疗等方式在脑胶质 瘤的治疗中已经取得较大的进展. 然而, 由于脑胶质瘤
的发病机制、临床症状及患者的身体状况各不相同, 仅用单一的治疗方法并不能达到理想效果, 这就需要 合理有机地结合多种治疗手段得到更高的治疗效率. 因此，协同疗法的出现对脑胶质瘤的临床治疗具有极 大的意义.

Lee课题组 ${ }^{[67]}$ 报道了通过脱氧胆酸偶联聚乙烯亚 胺纳米胶束共载姜黄素和microRNA-21(miR-21)反义 寡核苷酸用于脑胶质瘤的治疗(图6). 脑胶质瘤细胞高 表达miR-21, 而miR-21会抑制促调亡基因(如PTEN, $P D C D 4$ 等)的表达. 因此, miR-21被反义寡核苷酸敲低, 可诱导促凋亡基因表达，从而增加脑胶质瘤细胞的死 亡. 姜黄素, 一种从姜黄根中提取的活性天然疏水多 酚分子, 已被证明对脑胶质瘤具有肿瘤抑制作用 ${ }^{[68 \sim 70]}$. 该纳米复合物结构稳定, 粒径约为 $132 \mathrm{~nm}$. 体内与体外 实验结果证明, 该纳米药物能够有效降低miR21水平, 诱导脑胶质瘤细胞大量凋亡, 显著减小肿瘤体积, 产 生较好的治疗效果.

Shuai课题组 ${ }^{[71]}$ 以叶酸靶向的三嵌段共聚物(poly (ethylene glycol)-polyetherimide-poly( $\varepsilon$-caprolactone), PEG-PEI-PCL)为载体, 结合TMZ和抗BCL-2 siRNA, 以实现更好的胶质瘤治疗. BCL-2 是一种主要的抗调 


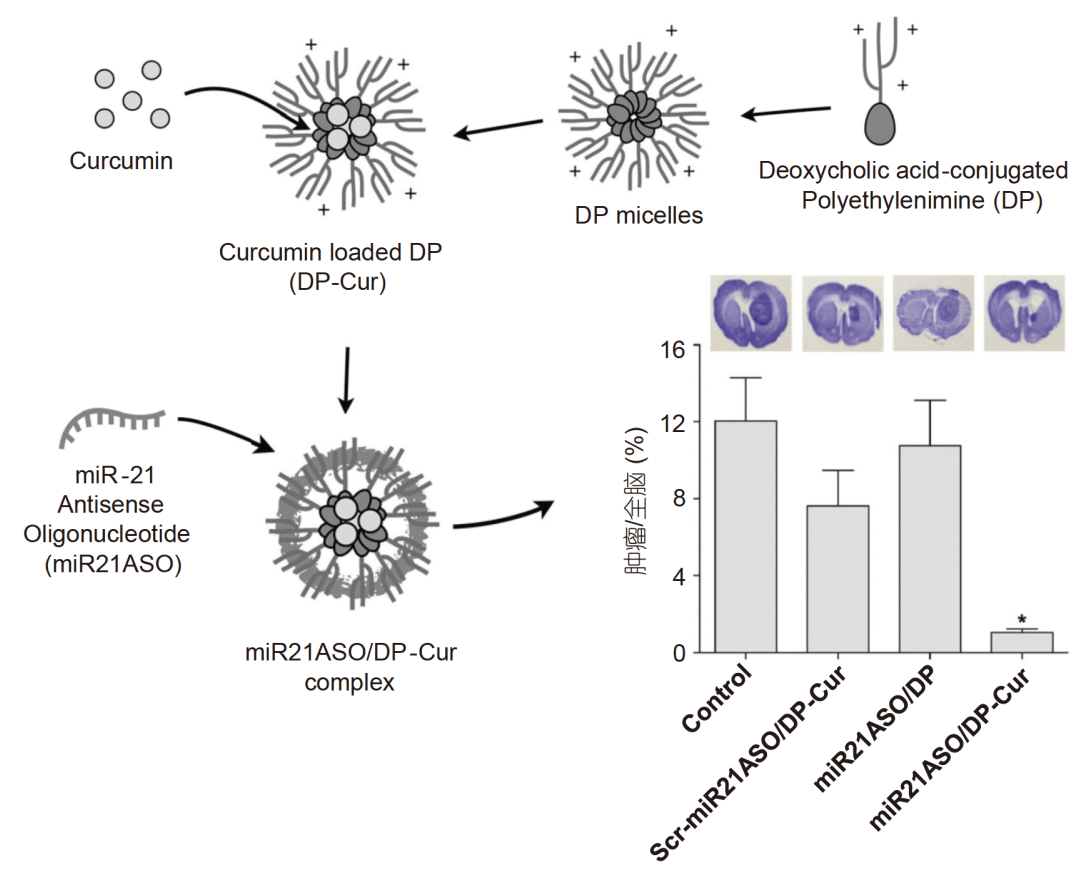

图 $6 \mathrm{miR} 21 \mathrm{ASO} / \mathrm{DP}-\mathrm{Cur}$ 复合物制备示意图以及不同实验组肿瘤大小占总脑的比重 ${ }^{[67]}$ (网络版彩图)

Figure 6 Schematic diagram of the preparation of the miR21ASO/DP-Cur complex and the proportion of tumor size in total brain in different experimental groups ${ }^{[67]}$ (Color online)

亡蛋白，能够阻碍凋亡激活因子的释放和线粒体细胞 色素 $\mathrm{C}$ 启动细胞凋亡蛋白酶的级联反应. 体内和体外 实验结果表明，该纳米药物能被C6胶质瘤细胞较好地 内吞，通过沉默 $B C L-2$ 基因，同时激活促调亡Bax基因， 使肿瘤细胞产生强烈的调亡反应，进而抑制肿瘤生长, 具有良好的抗胶质瘤作用. 以上研究结果均证明, 使用 化疗药物和基因治疗的联合治疗已显示出可以提高抗 脑胶质瘤效果的潜力.

Tedesco课题组 ${ }^{[72]}$ 报道了采用生物素和罗丹明-B 功能化嵌合P123/F127胶束共递送维替泊芬与TMZ, 用 于实现对脑胶质瘤的诊断与协同治疗一体化. 生物素 赋予该嵌段聚合物以主动靶向性，罗丹明-B用于脑胶 质瘤的诊断, 维替泊芬能够实现化学治疗的辅助光动 力治疗. 精确控制维替泊芬与TMZ的最佳配比，可对 脑胶质瘤细胞产生最有效的协同抗肿瘤作用. 实验结 果表明, 该纳米药物能够被T98G, U87MG, U343胶质 瘤细胞有效摄取, 产生较强的细胞毒作用. 光动力治疗 与TMZ化疗的协同作用能够有效杀死肿瘤细胞，同时 也克服了交叉耐药性. 这些结果表明, 光动力疗法辅 助治疗是改善以 TMZ为基础的脑胶质瘤治疗的一种 有前景的策略.
Yu课题组 ${ }^{[73]}$ 开发了一种基于高强度聚焦超声响 应释药的双靶向PLGA聚合物纳米载体, 负载Dox用于 增强脑胶质瘤的有效治疗. Angiopep-2是一种公认的 脑肿瘤靶向递送的双靶向分子, 高强度聚焦超声是一 种理想的药物释放触发器, 具有超高的能量和聚焦能 力. 在该项研究中, PLGA纳米颗粒具有良好的机械强 度和热稳定性, 被认为是较好的高强度聚焦超声响应 载体. 实验结果表明, 与未修饰的纳米粒子相比, 该双 靶向纳米药物BBB转运及脑胶质瘤内特异性积累分别 提高了17倍和13.4倍. 在高强度聚焦超声的作用下, 该 纳米复合物可在 $2 \mathrm{~min}$ 内释放 $47 \%$ 的药物, 诱导大多数 肿瘤细胞凋亡. 高强度聚焦超声触发抗癌药物的瞬时 释放, 使得经该纳米药物治疗的脑胶质瘤荷瘤小鼠肿 瘤大小占总脑的比重最小, 显示出较好的抗胶质瘤效 果. 聚焦超声结合化疗无疑为脑胶质瘤的治疗提供了 一条新途径, 具有很大的临床应用潜力.

\section{6 刺激响应性聚合物纳米载体用于脑胶质 瘤的治疗}

聚合物纳米载体通过化学治疗、基因治疗、免疫 
治疗等治疗方式极大地推进了其在脑胶质瘤治疗领域 中的应用. 然而, 随着研究的深入, 人们亦发现传统聚 合物纳米载体存在很多不足, 例如, 药物释放位置无选 择性、释放缓慢且不受控制等，造成抗癌药物的生物 利用率低、毒副作用大、易产生耐药性，严重阻碍了 聚合物纳米载体抗脑胶质瘤的进一步发展.

研究表明, 肿瘤组织具有多种与正常组织显著不 同的生理特征: 肿瘤组织 $(\mathrm{pH}$ 6.5 7.2) 和溶酶体/内涵 体( $\mathrm{pH}$ 5.0 6.5)比正常组织 $(\mathrm{pH}$ 7.4)偏酸; 肿瘤组织微 环境中酶浓度及活性均远远高于正常组织; 肿瘤细胞 中 GSH浓度 $(2 \sim 10 \mathrm{mmol} / \mathrm{L})$ 约为细胞外液体和血液中 (2 20 nmol/L)的100 1000倍. 基于此, 研究者们设计了 一系列基于 $\mathrm{pH}$ 敏感、还原敏感、酶敏感等刺激响应 性聚合物纳米载体，在血液环境下稳定，而在肿瘤组 织/肿瘤细胞内纳米载体快速降解, 触发释放药物, 最 终提高脑胶质瘤的抗肿瘤活性. Zhou课题组 ${ }^{[74]}$ 以 $\mathrm{pH}$ 和 GSH双响应性共聚物为原料构建了一种对肿瘤微环境 敏感的聚合物纳米胶束. 在肿瘤细胞溶酶体酸性条件 下，胶束中的3-(二丁基氨基)丙胺(3-(dibutylamino) propylamine, DBP)由疏水状态转化为亲水状态，可以 大大促进Dox的释放. 随后, 高浓度的GSH通过裂解胶 束中大量存在的二硫键导致负载的Dox和PLK1特异 性shRNA快速释放，有效地实现了充分发挥抗肿瘤作 用的同时对正常组织产生较小的毒副作用.

除根据肿瘤组织/细胞微环境特色设计的内在刺 激响应体系外，光敏感、超声敏感等外在刺激响应性
聚合物纳米载体也被开发并用于脑胶质瘤的治疗. 但 由于脑胶质瘤的特殊性, 近红外等光源渗透深度有限, 但超声响应体系渗透能力大大加强, 可有效解决这一 难题. Yu课题组 ${ }^{[73]}$ 设计了基于高强度聚焦超声响应释 药的双靶向PLGA聚合物纳米载体. 聚焦超声有效诱 导该纳米载体迅速释放负载的Dox, 使其在肿瘤部位 积累足够的剂量, 进而达到杀死肿瘤细胞的目的. 根 据刺激信号的不同，本文中涉及到的刺激响应性纳米 药物主要包括 $\mathrm{pH}$ 敏感、还原敏感、光敏感、超声敏 感等多种类型(表2).

\section{7 结语与展望}

截至目前，脑胶质瘤的治疗依然面临着巨大的挑 战. 聚合物纳米药物基于其能够增加药物稳定性与靶 向性、提高药物生物利用率、提高BBB和BBTB穿透 性等优势, 在脑胶质瘤的治疗中具有广阔的应用前景. 聚合物纳米药物可以通过多种方式治疗脑胶质瘤，本 文简要介绍了通过化学疗法、基因疗法、免疫疗法、 其他疗法、联合疗法及刺激响应性聚合物纳米药物用 于治疗脑胶质瘤所做的研究工作．每一种治疗方式都 能不同程度有效改善脑胶质瘤模型的中位生存期，然 而，将其用于临床胶质瘤治疗仍然有多种困难需要克 服. 首先，脑靶向效率低是纳米药物面临的首要问题， 尽管通过靶向剂修饰的纳米载体提高了其靶向性，但 BBB和BBTB对纳米递送系统的屏障作用仍然很强, 大

表 2 刺激响应性聚合物纳米载体类型汇总

Table 2 Summary of the classification of stimulation-responsive polymeric nanocarriers

\begin{tabular}{|c|c|c|c|}
\hline 刺激响应因素 & 敏感结构/物质 & 聚合物载体 & 参考文献 \\
\hline $\mathrm{pH}$ & 缩醛键 & Ac-DEX & {$[25]$} \\
\hline \multirow{3}{*}{ 还原性谷胱甘肽(GSH) } & 二硫化物 & polyMPC & {$[20]$} \\
\hline & 二硫键 & $\begin{array}{c}\text { 透明 } \\
\text { 质酸-S-S-二吡啶胺(锌) (HA-S-S-DPA(Zn)) }\end{array}$ & {$[51]$} \\
\hline & 二硫键 & $\begin{array}{c}\text { 聚羧酸甜莱碱-聚(N-(2-(2-吡啶二硫代)甲基丙烯酰胺乙酯 } \\
\text { (PCB-S-S-PDM-PDA) }\end{array}$ & {$[58]$} \\
\hline $\mathrm{pH}, \mathrm{GSH}$ & $\begin{array}{c}\text { 3-(二丁基氨基)丙胺(DBP) } \\
\text { 二硫键 }\end{array}$ & $\begin{array}{c}\text { 聚(环氧丙烷)- } b \text {-聚( }(\gamma \text {-芐基-L-谷氨酸)- } b \text { - 聚(乙二醇)三嵌段三元共 } \\
\text { 聚物(PPO- } b \text {-PBLG- } b \text {-PEG) }\end{array}$ & {$[74]$} \\
\hline 活性氧ROS & 苯硼酮酯基 & $\begin{array}{c}\text { 聚乙二醇-聚(氯化N-(3-甲基丙烯酰氨)胍, 4-(4, 4, 5, 5-四甲基-[1, } \\
3,2] \text { 二噁硼烷-2-基)-丙烯酸苄酯(PEG - } b \text {-P(Gu/Hb) }\end{array}$ & {$[52]$} \\
\hline 光照 & Lucirin $\mathrm{TPO}^{\circledR}$ & 纳米水凝胶(PEG-DMA/PLGA) & {$[31]$} \\
\hline 高强度聚焦超声(HIFU) & 全氟溴辛烷(PFOB) & PLGA & {$[73]$} \\
\hline
\end{tabular}


大限制了抗癌药物在脑中的富集. 因此, 探寻新型高效 的靶点或多重靶向系统的开发迫在眉睫. 其次, 脑胶质 瘤耐药性的存在也是纳米药物需要考虑的问题. 协同 治疗在一定程度解决了这个问题，但是多药耐药性形 成机制异常复杂，加上耐药性可能涉及全身多个系统， 往往很难实现理想的耐药逆转. 因此, 如何将聚合物纳 米载体更好地与抗癌药物结合，如何将多种治疗方式 更好地联合以及寻求更高效的刺激响应性制剂已成为 当务之急. 再次, 如何在现有聚合物材料的基础上设计 出更为简单多功能的纳米载体，在实现高效治疗的同
时又有利于产业化生产, 为聚合物纳米药物脑胶质瘤 临床转化打下基础, 是人们需要考虑的另外一个问题. 最后，目前的研究都仅在细胞、皮下或原位肿瘤移植 鼠、犬等动物模型进行了效果验证，但是鼠、犬与临 床病人差异性大，研究者们应致力于探究及应用更贴 近病人的人源移植模型等进行抗肿瘤实验，才能更快 速有效地篮选出合适的聚合物纳米制剂, 进行临床转 化并实现脑胶质瘤的安全、高效治疗. 本文相信, 随 着多种治疗方法的不断完善，脑胶质瘤的治疗将达到 新的高度, 这是一个艰巨而漫长的过程, 任重而道远.

\section{参考文献}

1 Weller M, Wick W, Aldape K, et al. Glioma. Nat Rev Dis Primers, 2015, 1: 15017

2 Saito T, Sugiyama K, Takeshima Y, et al. Prognostic implications of the subcellular localization of survivin in glioblastomas treated with radiotherapy plus concomitant and adjuvant temozolomide. J Neurosurg, 2017, 128: 679-684

3 Delgado-López P D, Corrales-García E M. Survival in glioblastoma: A review on the impact of treatment modalities. Clin Transl Oncol, 2016, 18: $1062-1071$

4 Ogura K, Mizowaki T, Arakawa Y, et al. Initial and cumulative recurrence patterns of glioblastoma after temozolomide-based chemoradiotherapy and salvage treatment: A retrospective cohort study in a single institution. Radiat Oncol, 2013, 8: 97

5 Herrlinger U, Tzaridis T, Mack F, et al. Lomustine-temozolomide combination therapy versus standard temozolomide therapy in patients with newly diagnosed glioblastoma with methylated $M G M T$ promoter (CeTeG/NOA-09): A randomised, open-label, phase 3 trial. Lancet, 2019, 393: 678-688

6 Peer D, Karp J M, Hong S, et al. Nanocarriers as an emerging platform for cancer therapy. Nat Nanotech, 2007, 2: 751-760

7 Oddo A, Peng B, Tong Z, et al. Advances in microfluidic blood-brain barrier (BBB) models. Trends Biotech, 2019, 37: 1295-1314

8 van Tellingen O, Yetkin-Arik B, de Gooijer M C, et al. Overcoming the blood-brain tumor barrier for effective glioblastoma treatment. Drug Resist Update, 2015, 19: 1-12

9 Beier D, Schulz J B, Beier C P. Chemoresistance of glioblastoma cancer stem cells-Much more complex than expected. Mol Cancer, 2011, 10: 128

10 Petros R A, DeSimone J M. Strategies in the design of nanoparticles for therapeutic applications. Nat Rev Drug Discov, 2010, 9: 615-627

11 Davis M E, Chen Z G, Shin D M. Nanoparticle therapeutics: An emerging treatment modality for cancer. Nat Rev Drug Discov, 2008, 7: 771-782

12 Shi J, Kantoff P W, Wooster R, et al. Cancer nanomedicine: Progress, challenges and opportunities. Nat Rev Cancer, 2016, 17: 20-37

13 Banik B L, Fattahi P, Brown J L. Polymeric nanoparticles: The future of nanomedicine. WIREs Nanomed Nanobiotechnol, 2016, 8: 271-299

14 Masood F. Polymeric nanoparticles for targeted drug delivery system for cancer therapy. Mater Sci Eng C, 2016, 60: 569-578

15 Mura S, Nicolas J, Couvreur P. Stimuli-responsive nanocarriers for drug delivery. Nat Mater, 2013, 12: 991-1003

16 Abbott N J, Rönnbäck L, Hansson E. Astrocyte-endothelial interactions at the blood-brain barrier. Nat Rev Neurosci, 2006, 7: 41-53

17 Abbott N J, Patabendige A A K, Dolman D E M, et al. Structure and function of the blood-brain barrier. Neurobiol Dis, 2010, 37: 13-25

18 Pardridge W M. The blood-brain barrier: Bottleneck in brain drug development. NeuroRx, 2005, 2: 3-14

19 Dai T, Jiang K, Lu W. Liposomes and lipid disks traverse the BBB and BBTB as intact forms as revealed by two-step Förster resonance energy transfer imaging. Acta Pharm Sin B, 2018, 8: 261-271

20 Ward S M, Skinner M, Saha B, et al. Polymer-temozolomide conjugates as therapeutics for treating glioblastoma. Mol Pharm, 2018, 15: 52635276

21 Ramalho M J, Sevin E, Gosselet F, et al. Receptor-mediated PLGA nanoparticles for glioblastoma multiforme treatment. Int J Pharm, 2018, 545: $84-92$

22 Ramalho M J, Loureiro J A, Coelho M A N, et al. Factorial design as a tool for the optimization of PLGA nanoparticles for the co-delivery of 
temozolomide and O6-benzylguanine. Pharmaceutics, 2019, 11: 401

23 Muniswamy V J, Raval N, Gondaliya P, et al. ‘Dendrimer-Cationized-Albumin' encrusted polymeric nanoparticle improves BBB penetration and anticancer activity of doxorubicin. Int J Pharm, 2019, 555: 77-99

24 Malinovskaya Y, Melnikov P, Baklaushev V, et al. Delivery of doxorubicin-loaded PLGA nanoparticles into U87 human glioblastoma cells. Int J Pharm, 2017, 524: 77-90

25 Zou Y, Liu Y, Yang Z, et al. Effective and targeted human orthotopic glioblastoma xenograft therapy via a multifunctional biomimetic nanomedicine. Adv Mater, 2018, 30: 1803717

26 Hassan M, Farid D, Mahdi A, et al. Methotrexate-loaded PLGA nanoparticles: Preparation, characterization and their cytotoxicity effect on human glioblastoma U87MG cells. Int J Med Nano Res, 2017, 4: 10-23937

27 Madani F, Goodarzi A, Hashemi M. Preparation of methotrexate loaded PLGA nanoparticles coated with PVA and poloxamer188. Nanomed Res J, 2018, 3: 19-24

28 Parmar A, Jain A, Uppal S, et al. Anti-proliferate and apoptosis triggering potential of methotrexate-transferrin conjugate encapsulated PLGA nanoparticles with enhanced cellular uptake by high-affinity folate receptors. Artif Cells Nanomed Biotech, 2018, 46: 704-719

29 Xin $\mathrm{H}$, Chen L, Gu J, et al. Enhanced anti-glioblastoma efficacy by PTX-loaded PEGylated poly(-caprolactone) nanoparticles: In vitro and in vivo evaluation. Int J Pharm, 2010, 402: 238-247

30 Yu J, Sun L, Zhou J, et al. Self-assembled tumor-penetrating peptide-modified poly(L- $\gamma$-glutamylglutamine)-paclitaxel nanoparticles based on hydrophobic interaction for the treatment of glioblastoma. Bioconjug Chem, 2017, 28: 2823-2831

31 Zhao M, Bozzato E, Joudiou N, et al. Codelivery of paclitaxel and temozolomide through a photopolymerizable hydrogel prevents glioblastoma recurrence after surgical resection. J Control Release, 2019, 309: 72-81

32 Chiani M, Toofani Milani A, Nemati M, et al. Anticancer effect of cisplatin-loaded poly (Butylcyanoacrylate) nanoparticles on A172 brain cancer cells line. Asian Pac J Cancer Prev, 2019, 20: 303-309

33 Feldhaeusser B, Platt S R, Marrache S, et al. Evaluation of nanoparticle delivered cisplatin in beagles. Nanoscale, 2015, 7: 13822-13830

34 Lee S Y. Temozolomide resistance in glioblastoma multiforme. Genes Dis, 2016, 3: 198-210

35 Chen X, Zhang M, Gan H, et al. A novel enhancer regulates MGMT expression and promotes temozolomide resistance in glioblastoma. Nat Commun, 2018, 9: 2949

36 Agudelo D, Bourassa P, Bérubé G, et al. Review on the binding of anticancer drug doxorubicin with DNA and tRNA: Structural models and antitumor activity. J Photochem Photobiol B, 2016, 158: 274-279

37 Jawad B, Poudel L, Podgornik R, et al. Molecular mechanism and binding free energy of doxorubicin intercalation in DNA. Phys Chem Chem Phys, 2019, 21: 3877-3893

38 Weaver B A. How taxol/paclitaxel kills cancer cells. Mol Biol Cell, 2014, 25: 2677-2681

39 Dasari S, Bernard Tchounwou P. Cisplatin in cancer therapy: Molecular mechanisms of action. Eur J Pharmacol, 2014, 740: 364-378

40 Zhu S, Pabla N, Tang C, et al. DNA damage response in cisplatin-induced nephrotoxicity. Arch Toxicol, 2015, 89: 2197-2205

41 Miller R P, Tadagavadi R K, Ramesh G, et al. Mechanisms of cisplatin nephrotoxicity. Toxins, 2010, 2: 2490-2518

42 Yin H, Kanasty R L, Eltoukhy A A, et al. Non-viral vectors for gene-based therapy. Nat Rev Genet, 2014, 15: 541-555

43 Barbalat R, Ewald S E, Mouchess M L, et al. Nucleic acid recognition by the innate immune system. Annu Rev Immunol, 2011, 29: 185-214

44 Bae Y, Thuy L T, Lee Y H, et al. Polyplexes of functional PAMAM dendrimer/apoptin gene induce apoptosis of human primary glioma cells in vitro. Polymers, 2019, 11: 296

45 Mastorakos P, Zhang C, Song E, et al. Biodegradable brain-penetrating DNA nanocomplexes and their use to treat malignant brain tumors. J Control Release, 2017, 262: 37-46

46 Yamamoto A, Kormann M, Rosenecker J, et al. Current prospects for mRNA gene delivery. Eur J Pharm Biopharm, 2009, 71: 484-489

47 Sayour E, Grippin A, Mendez-Gomez H, et al. Immu-63. Overcoming glioblastoma resistance to immune checkpoint blockade via RNA-loaded nanoparticles. Neuro Oncol, 2017, 19: vi126-vi127

48 Ibraheem D, Elaissari A, Fessi H. Gene therapy and DNA delivery systems. Int J Pharm, 2014, 459: 70-83

49 Hannon G J. RNA interference. Nature, 2002, 418: 244-251

50 Liu D Z, Cheng Y, Cai R Q, et al. The enhancement of siPLK1 penetration across BBB and its anti glioblastoma activity in vivo by magnet and transferrin co-modified nanoparticle. Nanomedicine, 2018, 14: 991-1003 
51 Zheng M, Yang Z, Chen S, et al. Bioreducible zinc(II)-dipicolylamine functionalized hyaluronic acid mediates safe siRNA delivery and effective glioblastoma RNAi therapy. ACS Appl Bio Mater, 2018, 2: 362-369

52 Zheng M, Liu Y, Wang Y, et al. ROS-responsive polymeric siRNA nanomedicine stabilized by triple interactions for the robust glioblastoma combinational RNAi therapy. Adv Mater, 2019, 31: 1903277

53 Chen Z, Liu F, Chen Y, et al. Targeted delivery of CRISPR/Cas9-mediated cancer gene therapy via liposome-templated hydrogel nanoparticles. Adv Funct Mater, 2017, 27: 1703036

54 Farkona S, Diamandis E P, Blasutig I M. Cancer immunotherapy: The beginning of the end of cancer? BMC Med, 2016, 14: 73

55 Sharma P, Allison J P. The future of immune checkpoint therapy. Science, 2015, 348: 56-61

56 Wang X, Xiong Z, Liu Z, et al. Angiopep-2/IP10-EGFRvIIIscFv modified nanoparticles and CTL synergistically inhibit malignant glioblastoma. Sci Rep, 2018, 8: 12827

57 Li T F, Xu Y H, Li K, et al. Doxorubicin-polyglycerol-nanodiamond composites stimulate glioblastoma cell immunogenicity through activation of autophagy. Acta Biomater, 2019, 86: 381-394

58 Shen Q, Yang J, Liu R, et al. Hybrid 'clusterbombs' as multifunctional nanoplatforms potentiate brain tumor immunotherapy. Mater Horiz, 2019, 6: $810-816$

59 Galstyan A, Chiechi A, Korman A J, et al. Nano immunoconjugates crossing blood-brain barrier activate local brain tumor immune system for glioma treatment. BioRxiv, 2018

60 Cai X, Bandla A, Chuan C K, et al. Identifying glioblastoma margins using dual-targeted organic nanoparticles for efficient in vivo fluorescence image-guided photothermal therapy. Mater Horiz, 2019, 6: 311-317

61 Lai J, Deng G, Sun Z, et al. Scaffolds biomimicking macrophages for a glioblastoma NIR-Ib imaging guided photothermal therapeutic strategy by crossing blood-brain barrier. Biomaterials, 2019, 211: 48-56

62 Kessel D. Apoptosis, paraptosis and autophagy: death and survival pathways associated with photodynamic therapy. Photochem Photobiol, 2019, 95: $119-125$

63 Bœuf-Muraille G, Rigaux G, Callewaert M, et al. Evaluation of mTHPC-loaded PLGA nanoparticles for in vitro photodynamic therapy on C6 glioma cell line. Photodiagnosis Photodyn Ther, 2019, 25: 448-455

64 Rengeng L, Qianyu Z, Yuehong L, et al. Sonodynamic therapy, a treatment developing from photodynamic therapy. Photodiagnosis Photodyn Ther, 2017, 19: 159-166

65 Liu H L, Hua M Y, Chen P Y, et al. Blood-brain barrier disruption with focused ultrasound enhances delivery of chemotherapeutic drugs for glioblastoma treatment. Radiology, 2010, 255: 415-425

66 You D G, Deepagan V G, Um W, et al. ROS-generating TiO2 nanoparticles for non-invasive sonodynamic therapy of cancer. Sci Rep, 2016, 6: 23200

67 Tan X, Kim G, Lee D, et al. A curcumin-loaded polymeric micelle as a carrier of a microRNA-21 antisense-oligonucleotide for enhanced antitumor effects in a glioblastoma animal model. Biomater Sci, 2018, 6: 407-417

68 Zanotto-Filho A, Braganhol E, Edelweiss M I, et al. The curry spice curcumin selectively inhibits cancer cells growth in vitro and in preclinical model of glioblastoma. J Nutr Biochem, 2012, 23: 591-601

69 Dhandapani K M, Mahesh V B, Brann D W. Curcumin suppresses growth and chemoresistance of human glioblastoma cells via AP-1 and NFkB transcription factors. J Neurochem, 2007, 102: 522-538

70 Khaw A K, Hande M P, Kalthur G, et al. Curcumin inhibits telomerase and induces telomere shortening and apoptosis in brain tumour cells. J Cell Biochem, 2013, 114: 1257-1270

71 Peng Y, Huang J, Xiao H, et al. Codelivery of temozolomide and siRNA with polymeric nanocarrier for effective glioma treatment. Int J Nanomedicine, 2018, 13: 3467-3480

72 Pellosi D S, Paula L B, de Melo M T, et al. Targeted and synergic glioblastoma treatment: Multifunctional nanoparticles delivering verteporfin as adjuvant therapy for temozolomide chemotherapy. Mol Pharm, 2019, 16: 1009-1024

73 Luo Z, Jin K, Pang Q, et al. On-demand drug release from dual-targeting small nanoparticles triggered by high-intensity focused ultrasound enhanced glioblastoma-targeting therapy. ACS Appl Mater Interfaces, 2017, 9: 31612-31625

74 Wang P, Yu N, Wang Y, et al. Co-delivery of PLK1-specific shRNA and doxorubicin via core-crosslinked pH-sensitive and redox ultra-sensitive micelles for glioma therapy. J Mater Chem B, 2018, 6: 112-124 


\title{
Recent advances in polymeric nanomedicines for glioblastoma therapy
}

\author{
SUN YaJing, WANG YiBin, LIU YanJie, ZOU Yan, ZHENG Meng \& SHI BingYang \\ International Joint Center for Biomedical Innovation, School of Life Sciences, Henan University, Kaifeng 475004, China
}

Glioblastoma (GBM) is the most common primary malignant tumor with high mortality. Currently, the treatment for GBM displays poor prognosis which is difficult to achieve a satisfied therapeutic effect. Nanomedicines based on polymers have opened up new strategies for GBM therapy due to their unique features such as good biocompability, easy designation and synthesis, feasible ligand functionalization, efficient blood brain barrier (BBB) penetration. Polymeric nanocarriers boost efficient antitumor efficacy via encapsulate/conjugate therapeutics including small molecule anticancer drugs, nucleic acids (DNA, siRNA) and proteins. Here, we review the research progress of chemotherapy, gene therapy, immunotherapy, synergistic therapy as well as various stimuli responsive polymeric nanosystems for GBM over recent years, and also prospect for their future development.

polymer, nanomedicine, glioblastoma (GBM), therapy methods

doi: $10.1360 /$ SSV-2019-0212 